2-16-2019

\title{
Interest-enhancing approaches to mathematics curriculum design: Illustrations and personalization
}

Virginia Clinton

University of North Dakota, virginia.clinton@und.edu

Candace Walkington

\section{How does access to this work benefit you? Let us know!}

Follow this and additional works at: https://commons.und.edu/efr-fac

Part of the Science and Mathematics Education Commons

\section{Recommended Citation}

Virginia Clinton and Candace Walkington. "Interest-enhancing approaches to mathematics curriculum design: Illustrations and personalization" (2019). Educational Foundations and Research Faculty Publications. 8.

https://commons.und.edu/efr-fac/8

This Article is brought to you for free and open access by the Department of Educational Foundations and Research at UND Scholarly Commons. It has been accepted for inclusion in Educational Foundations and Research Faculty Publications by an authorized administrator of UND Scholarly Commons. For more information, please contact und.commons@library.und.edu. 


\section{ILLUSTRATIONS AND PERSONALIZATION}

\section{Running Head: ILLUSTRATIONS AND PERSONALIZATION}

Interest-enhancing approaches to mathematics curriculum design: Illustrations and personalization

Virginia Clinton

University of North Dakota

Candace Walkington

Southern Methodist University

Author's note. Virginia Clinton is an Assistant Professor in Educational Foundations and Research at the University of North Dakota. She may be contacted at (701) 777-5793, virginia.clinton@und.edu, or 231 Centennial Dr., Grand Forks, ND, 58202, USA. 


\section{Please cite as the following:}

Clinton, V. \& Walkington, C. (in-press). Interest-enhancing approaches to mathematics curriculum design: Illustrations and personalization. The Journal of Educational Research. doi: 10.1080/00220671.2019.1568958

The Version of Record of this manuscript has been published and is available in The Journal of Educational Research. doi: 10.1080/00220671.2019.1568958 


\begin{abstract}
Two common interest-enhancement approaches in mathematics curriculum design are illustrations and personalization of problems to students' interests. The objective of these experiments is to test a variety of illustrations and personalization approaches. In the illustrations experiment, students $(N=265)$ were randomly assigned to lessons with story problems containing decorative illustrations, contextual illustrations, diagrammatic illustrations, misleading illustrations, or no illustrations (only text; control). Students' problem-solving performance and attitudes were not affected by illustration condition, but learning was better in the control compared to contextual illustrations. In the personalization experiment, students $(N=$ 223) were randomly assigned to story problems that were either personalized based on: a survey of their interests, their choice of interest topics, a randomly-assigned interest topic, or the original non-personalized story problem (control). The findings indicated there were benefits for choice personalization both for performance in the problem set as well as on a later learning assessment.
\end{abstract}

Keywords: middle school mathematics; word problems; interest; personalization; visual representations 


\section{Interest-enhancing approaches to mathematics curriculum design: Illustrations and personalization}

Recent research has revealed how many students tend to disengage with mathematics learning over adolescence (Deieso \& Fraser, in-press; Frenzel, Gotez, Pekrun, \& Watt, 2010), and increasingly have difficulty seeing the relevance of mathematics to their lives (McCoy, 2005). Accordingly, methods of increasing interest in educational contexts has been an important topic in educational psychology (Harackiewicz, Smith, \& Priniski, 2016). Some interventions to enhance students' interest in curricular materials include adding colorful illustrations (Durik \& Harackiewicz, 2007), personalizing instruction to students' out-of-school interests in topics like sports or music (Walkington, 2013), and giving learners control and choice in their learning activities (Patall, 2013; Potvin \& Hasni, 2014). Although many of these interventions have shown promise for eliciting interest, consideration is not always given to the cognitive implications of these modifications. Better understanding of these modifications would be informative for curriculum design.

Specifically, features designed to enhance interest may become seductive details (Harp \& Mayer, 1998; Lehman, Schraw, McCrudden, \& Hartley, 2007) and distract learners from grappling with the mathematical concepts that should be their central focus. In addition, if learners become accustomed to these kinds of interest-enhancing supports that provide context, they may struggle in situations where they must solve abstract mathematics problems, as described in learning theories related to desirable difficulties (Schmidt \& Bjork, 1992). Research on desirable difficulties suggests that learners may benefit more in the long term from a lack of support in their learning environment, as this forces them to truly grapple with key concepts and 
make important conceptual connections on their own (e.g., Fyfe \& Rittle-Johnson, 2017;

Schweppe \& Rummer, 2016).

In the present set of two experiments, we examine several interest-enhancing

interventions - including illustrations, personalization, and choice - in an online curriculum for middle school mathematics. We examine the short-term effects of these modifications - whether the interest enhancement is supportive or not for solving the intervention activities - as well as the long-term effects on student learning - whether the interest enhancement is a crutch or a scaffold for subsequent assessments of learning from the intervention problems. Both short-term and long-term outcomes like these are critical considerations for curriculum designers, particularly as interest-enhancements have become more common in online materials where technology can allow for adaptivity and choice. We next review the relevant literature relating to spurring interest and ensuring coherence during learning activities.

\section{Theoretical Framework}

\section{Interest Theory}

As students become increasingly disengaged with mathematics over adolescence, one response from instructional designers may be to design materials that elicit students' interestdefined as the state of engaging and the predisposition to re-engage with particular objects, events, topics, or ideas (Hidi \& Renninger, 2006). Higher levels of interest have been associated directly with improved performance and learning (Harackiewicz, Durik, Barron, Linnenbrink, \& Tauer, 2008; Potvin \& Hasni, 2014). Kim, Jiang, and Song (2015) analyzed a large dataset and found interest in mathematics to be predictive of achievement in middle and high school math.

Higher interest is connected to important mediators of learning like attention, engagement, persistence, perceived competence, and use of learning strategies (Flowerday \& 
Shell, 2015; Kim et al., 2015; Linnenbrink-Garcia, Patall, \& Messersmith, 2013), and with variables like self-efficacy, self-regulation, and achievement goals (Sommet \& Elliot, 2017; Hidi \& Ainley, 2008). Modifying instructional materials using approaches like personalization and visuals can elicit affective changes like increased engagement associated with triggered situational interest, which is also characterized by persistence, focused attention (Ainley, Hidi, \& Berndorff, 2002; Hidi \& Renninger, 2006), and improved learning (Heddy, Sinatra, Seli, Taasoobshirazi, \& Mukhopadhyay, 2017). This interest could increase motivation to engage in solving the problems (see Mayer, 2014a, for discussion). Interest can be triggered by task characteristics - including task characteristics that are salient, personally relevant, surprising, evocative, or concrete (Hidi \& Renninger, 2006). Developing testing task characteristics that can trigger situational interest is important, because initial interest in mathematics lessons could prompt later motivation to engage in mathematics (Bernacki \& Walkington, 2018; Mayer, 2014a; Rotgans \& Schmidt, 2017). Motivation to engage in content has been shown to promote full use of cognitive resources and deeper processing of the content (Clinton, 2015; Mayer, 2014a; Miele \& Wigfield, 2014). Therefore, it is possible that the inclusion of interest-enhancing triggers (such as visuals and personalization) could enhance learning because of increases in motivation.

\section{The Coherence Principle and Desirable Difficulties}

Although we normally think about higher interest as consistently being beneficial in educational settings, it has also been observed that interest enhancements in mathematics may only be tenable if they are relevant to the content to be learned (Mitchell, 1993), rather than being extraneous. For example, Walkington and Bernacki (2014) describe how personalization can be implemented deeply by examining how students actually use academic concepts in their day-to-day life, or in a shallow manner by swapping interesting popular culture terms into 
problems. Such shallow approaches to personalization have shown gains in reported interest, with no reported increase in learning (e.g., Høgheim \& Reber, 2015). Similarly, instructional materials can be made more interesting by making them colorful with interesting fonts or decorative graphics (e.g., Durik \& Harackiewicz, 2007; Magner, Schwonke, Aleven, Popescu, \& Renkl, 2014) or by adding in meaningful visuals that display key relationships and ideas in the domain (Booth \& Koedinger, 2012). This captures the idea that more interest may not always be beneficial - students need to be supported in focusing on domain-relevant principles rather than superficial, exciting features (Walkington et al., 2014). In this way, meaningful visuals would likely be a more effective interest-enhancing approach for learning than irrelevant, yet appealing pictures.

This idea is supported to research previously alluded to on seductive details and desirable difficulties. The seductive detail effect (Harp \& Mayer, 1998) is the idea that adding interesting but irrelevant information to learning materials may hamper performance by increasing cognitive processing demands that are extraneous. This leads to Mayer's (2017) coherence principle, which states that learning will be enhanced when extraneous words, pictures, or sounds are removed from learning materials. Perceptually rich learning materials may thus be harmful to learning, although this effect may be moderated by student characteristics (Cooper, Sidney, \& Alibali, 2018; McNeil, Uttal, Jarvin, \& Sternberg, 2009; Petersen \& McNeil, 2013; Son \& Goldstone, 2009).

Research on desirable difficulties (Bjork, 2018) takes the somewhat provocative stance that in-the-moment enhancements to students' speed or accuracy while they are in the process of learning may not be predictive of how much they actually learn - their long-term retention or transfer. Instead, a cognitively challenging learning experience where students struggle and 
encounter difficulty may optimally support their long-term growth and learning. Researchers who take this perspective (e.g., Walkington, 2013) often make a distinction between "performance" (i.e., how the student performs immediately on modified problems) and "learning" (i.e., how the student performs later on, once the intervention is removed). However, what makes a difficulty "desirable" or "undesirable" is subject to a host of contextual factors, making research in this area somewhat problematic (McDaniel \& Butler, 2010). Thus, we next review the available evidence on two sources of interest-enhancement in mathematics, visual representations and personalization, on learning outcomes.

\section{Literature Review}

\section{Visual Representations}

One way in which curriculum designers seek to make materials more interesting is through visual representations such as illustrations. Middle school mathematics materials in the United States often contain illustrations that do not convey mathematical information that are intended to enhance interest (Clinton \& Cooper, 2015; Mayer, Sims, \& Tajika, 1995). These illustrations may be solely decorative (e.g., a picture of a student smiling) and intended to make the materials more appealing (Schneider, Nebel, \& Rey, 2016). Considerable support has been found for the coherence principle regarding the removal of purely decorative illustrations to improve student learning, which are often referred to as seductive details (Berends \& van Lieshout, 2009; Jaeger \& Wiley, 2014; for a review, see Rey, 2012).

In addition to decorative illustrations, mathematics materials often have contextual illustrations intended to both enhance interest and to assist with comprehension. Contextual illustrations, also referred to as representational illustrations, convey information related to the story problem or lesson (e.g., a picture of a tent next to a story problem involving camping; 
Clinton, Michaelis, Cooper, Alibali, \& Nathan, 2017; Cooper et al., 2018). Although there is evidence contextual illustrations enhance interest (Walkington, Cooper, \& Howell, 2013; Walkington, Cooper, Nathan, \& Alibali, 2015), the influence of contextual illustrations on mathematics performance and learning is a complex issue. There is evidence that contextual illustrations may aide in comprehension, at least for narratives (Pike, Barnes, \& Barron, 2010). Furthermore, scientific problem solving appears to be facilitated when critical information is portrayed in contextual illustrations compared to only text (Lindner, Ihme, Saß, \& Koller, 2016; Saß, Wittwer, Senkbeil, \& Köller, 2012). However, in studies in which middle school students solved problems that required applying real-world information, there was no effect of contextual illustrations on realistic answers (Dewolf, van Dooren, Ev Cimen, \& Verschaffel, 2014). Based on analyses of interviews with middle school students, it appears that contextual illustrations are often not perceived by students as helpful for problem solving (Dewolf, 2014).

One way in which contextual illustrations may be applied and be both helpful and interesting would be to have them convey relevant mathematical information in addition to providing perceptually-rich representations (Dewolf et al, 2014). In this way, a diagrammatic illustration (i.e., a contextual illustration with mathematical information) could provide scaffolding for problem solving as well as interest enhancement through perceptually rich features (Cooper et al., 2018). There is limited research specifically examining diagrammatic illustrations (see Cooper et al., 2018 for an exception), but there is a wealth of research on diagrams. Research into the effects of diagrams in middle school mathematics includes topics such as the creation of schematic diagrams for spatially-oriented arithmetic word problems (Boonen, van Wesel, Jolles, \& van der Schoot, 2014), the use of diagrams in algebra word problems (Booth \& Koedinger, 2012), and the use of diagrams in proportional reasoning tasks 
(Jitendra \& Star, 2012). Generally speaking, diagrams appear to be helpful for mathematics learning and problem-solving performance, provided the diagram is understood by the student (Booth \& Koedinger, 2012; Clinton, Alibali, \& Nathan, 2016; Cooper et al., 2018). Indeed, effectively using visual representations in one way in which to improve problem solving by middle school students (Woodward et al., 2012). Indeed, effectively using visual representations is one way in which to improve problem solving in middle school (Woodward et al., 2012). Therefore, a diagrammatic illustration may be both helpful for mathematics performance and interest enhancing.

Research Questions and Hypotheses. In the first experiment reported in this manuscript on curriculum design techniques to enhance interest, we examine these complex issues by comparing a variety of types of illustrations accompanying story problems. Based on our observations that contextual illustrations often portray inaccurate mathematical information, a category of misleading illustrations were included (see Kajander \& Lovric, 2009, for a discussion of how visuals can foster misconceptions in mathematics) in addition to decorative, contextual, and diagrammatic illustrations. There was also a control in which no illustrations (or any other type of visual) accompanied the problems.

To have a robust understanding of student experiences with these visuals, we addressed two research questions. The first research question regarding interest-enhancing approaches in curriculum design was: How do different types of illustrations or no illustration alongside story problems at all affect students' immediate problem-solving accuracy and their learning as indicated through performance on a later assessment without illustrations? Our first hypothesis, the diagrams hypothesis, was that the diagrammatic illustrations would be helpful for problemsolving performance as they provided information relevant to the mathematics and the context of 
the story problem, which would make the problems more comprehensible and subsequently more interesting (Connelly, 2011; Magner, Glogger, \& Renkl, 2016). Based on the coherence principle (Mayer, 2014b), another hypothesis, the irrelevance hypothesis, was that the irrelevant illustrations intended to enhance interest—-both those that are misleading (with inaccurate mathematic information portrayed) and those that were purely decorative (unrelated to either the context of the story problem or the mathematics) - were predicted to interfere with learning both for solving the intervention problems and for later learning assessments.

One concern is that visuals which communicate information relevant to the lesson, whether these visuals be mathematically relevant diagrams or contextual illustrations, may actually interfere with learning as measured on later assessments. This is because struggling to understand the problem may be a desirable difficulty that could improve long-term learning, which would be shown on later assessments (e.g., Schweppe \& Rummer, 2016). For this reason, we developed the text alone hypothesis in which a lack of support from visuals during the learning process, would lead to better performance on later assessments of learning.

The second research question regarding interest-enhancing approaches in curriculum design was: How does the presence of an illustration, intended to be interesting, compared to no visual at all affect students' attitudes towards the story problems? Here we hypothesized that that including an illustration, whether decorative, contextual, diagrammatic, or misleading, with a story problem would yield more positive student attitudes than a story problem with only text (illustrations and interest hypothesis). This hypothesis was based on previous research findings that adding illustrations may improve attitudes towards the lesson (Durik \& Harackiewicz, 2007; Magner et al., 2014).

These four hypotheses will guide our first experiment of the curriculum design approach 
to enhance interest through illustration in mathematics story problems. We now turn to the interest-enhancement methods for curricula used for our second study - personalization and choice.

\section{Personalization and Choice}

One curriculum design method to enhance student interest in mathematics is personalization. Personalization is an instructional approach that connects mathematics tasks to students' out-of-school interests in topics such as sports, shopping, and video games (Walkington, 2013). Walkington and Bernacki (2014) discussed the three important curriculum design criteria for interventions seeking to personalize learning. The first criterion is a consideration of the depth of the personalization intervention - whether the intervention is designed to elicit and draw upon the deep knowledge students have of actually pursuing their interest area, or whether the intervention merely taps into surface features of their interest area (by, for example, simply inserting words into learning tasks related to this interest). The second criterion is a consideration of the ownership of the intervention - whether students take an active role in personalizing their own learning, or whether the personalization is imposed upon them by the outside with little student control of the learning experience. The third criterion is a consideration of the grain size of the intervention - whether the intervention is intended to be broadly personalized to the interests of all members of a particular age group, school, or class, or whether the intervention truly utilizes adaptivity to match instruction to an individual's specific and unique interests. We next discuss prior research on personalization using these three criteria as a lens for interpreting research results.

Depth. In one of the most well-known studies of personalization and choice, Cordova and Lepper (1996) found that personalizing instruction on order of operations to elementary 
students' interests (accomplished by replacing words in problem tasks with words students filled in on questionnaires) enhanced learning on a post-test compared to a control condition. They further found that students in conditions where they were given choice over incidental aspects of the problem scenarios performed significantly higher at post-test than those given no choice, suggesting that students' level of ownership is an important factor in promoting learning. Similar findings for the benefit of personalized problems were also reported for arithmetic word problems involving addition and subtraction around the same time period (Anand \& Ross, 1987; Davis-Dorsey, Ross, \& Morrison, 1991). However, later studies have shown null effects on learning for personalized learning interventions of this type (Bates \& Wiest, 2004; Caker \& Simsek, 2010, Ku \& Sullivan, 2000; Reber, Hetland, Chen, Norman, \& Kobbeltvedt, 2009).

Walkington (2013) conducted a study of personalization to ninth grade students' interests in the Cognitive Tutor Algebra software. The study found both short-term performance and longterm learning gains for the personalization condition compared to the control condition. In a follow-up study, Bernacki and Walkington (2018) found that personalization triggered students' immediate interest in the learning task, and enhanced the efficiency (time) at which the students learned. This triggered interest became maintained over time, and over the course of the school year transformed into interest in the domain of mathematics. Through these pathways, receiving personalization had a small effect on paper-based classroom assessments. These two studies had a greater depth than the studies previously reviewed with null effects on learning (Bates \& Wiest, 2004; Caker \& Simsek, 2010, Ku \& Sullivan, 2000; Reber et al., 2009), as problem contexts were developed based on interviews and surveys with students at the school site about how they actually used numbers and quantities while pursuing their interest areas. However, Walkington and Bernacki (2018) compared deep versus shallow personalization in Cognitive Tutor Algebra, 
and found that deep personalization was only better if students had sufficiently deep prior knowledge of how numbers were used in their interest areas.

Grain Size. In terms of grain size, Lopez and Sullivan (1992) found that both individualand group-level personalization supported performance over a control group, but that these two conditions were not significantly different from each other. Group-level personalization involved connecting instruction to the interests of groups of students, rather than individual students, thus had a larger grain size. In more recent work, Walkington and colleagues (2015) examined if there were particular broad topics for algebra story problems that adolescents generally performed better on. Story problems involving socializing and home and family contexts were generally associated with higher performance than scenarios involve physics, banking, or business, although effect sizes were small. This suggests that personalization at a broad grain size - where students receive problems based on group-level interests rather than receiving problems specifically tailored to individual interests, may still be an effective strategy for improving student learning.

Ownership. Walkington and Bernacki (2015) and Walkington and Hayata (2017) conducted studies in which students posed, solved, and shared problems related to their interests during pull-out interviews. They found that students who learned from the activity and who were successful at the activity typically had deeper knowledge of their interest areas, sufficient prior mathematical knowledge, and an understanding of the norms surrounding how to write clear and solvable school math problems. Following this research, Walkington (2017) reported a classroom intervention in which middle school students posed, solved, and shared algebra problems related to their interest areas, and found positive effects for both interest and learning compared to a business as usual condition. This personalization had great depth - as students 
were posing problems related to how they used numbers in everyday contexts they encountered and significant student ownership - as students were writing the problems themselves. The grain size was medium, as students posed the problems in groups with other students who shared their same interest area. Manipulating the depth, grain size, and ownership of personalization interventions to enhance interest seems to have an important impact on outcomes.

Research question and hypotheses. The research question for the second experiment on the interest-enhancement approach of curriculum design through personalization of this manuscript was: How do different approaches to personalization affect students' accuracy on personalized problems and their performance on a non-personalized later assessment? To address this research question, sixth grade students received either (1) normal, non-personalized problems in Reasoning Mind (control), (2) problem variations selected to be matched to their interests based on an interests survey they had responded to earlier (survey personalization), (3) random personalized problem variations not selected via a survey (random personalization), or (4) personalized problems relating to topics of their choice (i.e., they could choose which problem they wanted to solve; choice personalization).

We tested the depth of the personalization with two different problems. Students in each of the four conditions received two tasks as part of the intervention. We designed one task to be shallow and to tap into students' interest area in a shallow manner only. The other task was designed to be deep and describe a specific, detailed, and engaging story about their interest area. Our hypothesis (the depth hypothesis) is that personalization of the story context to student interests (either determined by choice or survey) will have a larger effect for the deep personalized task than for the shallow personalized task. 
The four conditions varied in the ownership of the personalization, or the degree of choice. The control and random personalization conditions had little or no student ownership, as students had no real input into their learning task and its degree of match to their interests. The survey personalization condition might have a very low level of ownership, if students recalled taking the interests survey and realized that tasks were being assigned to them based on their preferences. The choice personalization condition had a higher level of ownership - students took an active role in determining which personalized problem they wanted to solve and thus were able to exhibit control over their learning experiences. Our second hypothesis (ownership hypothesis) is that the condition with a high level of ownership (choice personalization) will outperform the other conditions on both solving the intervention problems and performance on a later assessment of learning from these problems.

The grain size of the personalization varied in the conditions. In the control condition, the grain size was very broad - students received problems on whatever topics the curriculum designers deemed appropriate. In the random personalization condition, the grain size was somewhat broad - students received problems written by researchers with an explicit goal of being relevant to the interests of students of this age group, but not problems that were selected to be relevant to their particular interests. In the survey personalization and choice personalization conditions, the grain size was smaller - students received problems that were personalized to particular topics they expressed interest in either on a survey, or when they selected their own problem. Our third hypothesis (grain size hypothesis) was that smaller grain size conditions (survey and choice personalization conditions) would outperform larger grain sized (control and random personalization conditions) on both solving the intervention problems and performance on a later assessment of learning from these problems. 
Because of the benefits of desirable difficulties, it is possible that interest-enhancement approach personalization would benefit performance on the intervention problems, but interfere with performance on a later learning assessment (Schmidt \& Bjork, 1992). This is because the motivational support provided by problems personalized to interests could prevent students from struggling with the content in a productive manner that could engage them more deeply (Walkington \& Bernacki, 2018). Moreover, the students could become accustomed to personalization (as in the survey personalization and choice personalization conditions) or topics designed to interesting for their age group (as in the random personalization condition) and the items on a later assessment would not be interesting. For this reason, we developed a counter hypothesis (the no personalization hypothesis) to previous ones expecting benefits from personalization. Based on the no personalization hypothesis, solving problems in the control condition would yield better performance on the later assessment than the other conditions.

In this manuscript, we expand on previous research on interest-enhancement in curriculum design by examining several different types of illustrations and several different approaches to personalization in an online, adaptive mathematics curriculum, and examine their effect not only on immediate performance on intervention problems, but on later performance on assessments as well. In this way, we are testing a variety of approaches enhancing interest in mathematics problem-solving and learning that are afforded in online adaptive curricula. By examining a variety of approaches, we can have a comprehensive examination to help guide decisions of curriculum designers. We specifically examine whether interest enhancements that may benefit students in the short-term - like visuals and personalization - have lasting effects on student learning.

\section{Method}




\section{Context}

Both studies took place within the Reasoning Mind $6^{\text {th }}$ grade curricula, dubbed "Genie 3." Reasoning Mind is a mathematics blended learning system developed by a nonprofit organization of the same name. Within this system, students study mathematics on computers during their mathematics class time while their teacher is free to conduct targeted interventions with students or groups who are struggling with a concept. Typically, there were 20-25 students in a class. The system is worked with in school where students have access to the classroom computers to use the curricula. The amount of mathematics instruction and time devoted to the Reasoning Mind curriculum varied by class.

In Genie 3, the student is immersed in a lesson environment that includes a tutor character, two other student characters, and a virtual blackboard. The three characters are scripted and speak (narrated by human voices) to each other and to the student, simulating a small tutoring session. They also write on and point to things written on the virtual board with animated markers. The student characters make common mistakes which the real student is asked to correct, these student characters also help the real student when he or she has difficulty with the material, and they interact with the real student and the tutor in ways that promote beneficial mathematical attitudes and beliefs (see Figure 1 for a screenshot of Genie 3). This rich interactive environment provides a social context which allows students using Genie 3 to engage in the key practices of mathematical work and reasoning embodied in the Common Core Standards for Mathematical Practice (Common Core Standards for Mathematical Practice, 2015). It also incorporates research-supported principles of online curriculum design: the use of audio to complement written text and explain visual illustrations (Clark \& Mayer, 2016), instruction coming from socially convincing pedagogical agents using polite, direct, and informal speech 
(Wang, Johnson, Mayer, Rizzo, Shaw, \& Collins, 2008), use of gestures to help connect auditory and visual information (Peeters, Snijders, Hagoort, \& Özyürek, 2017; see Mulqueeny, Kostyuk, Baker, \& Ocumpaugh, 2015). Independent evaluations found that the program improves student performance on mathematics assessments (Boriack, Stillisano, Wright, \& Waxman, 2015; Waxman \& Houston, 2012; see Khachatryan et al., 2014). Quantitative field observations of student affect and engagement have found that students using Reasoning Mind were on task and engaged more often than the average for traditional or other blended learning classes (Mulqueeny et al., 2015).

\section{Participants}

Both experiments took place in two small urban middle schools in the United States. Experiment 1 (visuals) involved $2656^{\text {th }}$ grade students, while Experiment 2 (personalization) involved $2236^{\text {th }}$ grade students. The demographic makeup of each school (both involved in both experiments) is presented in Table 1.

\section{Experiment 1: Visuals}

Materials. Experiment 1 included 4 fractions tasks across Lessons 88 and 89 of the curriculum. All four tasks gave a fractional measurement (e.g., $3 / 8$ of a meter), and then described what part of a whole this measurement was (e.g., was 21/40 of the whole length). The students then had to solve for the whole (see Figure 2 for an example). Students were randomly assigned to one of five conditions (see Figure 2): 1) a control condition with no illustrations for the 4 tasks (text only control), 2) a condition with illustrations related to the story context and contained no mathematical information (contextual illustration), 3) a condition with diagrammatic illustrations that contained correct mathematical information (diagrammatic illustration) 4) a condition with diagrammatic illustrations that contained incorrect mathematical 
information (misleading illustration), and 5) a condition with illustrations that had nothing to do with the story context (irrelevant illustration). The misleading illustration condition was added based on the observation that some of the illustrations already in the curriculum were actually misleading - for example, there would be a task about a snake who had one third of his length wrapped around a pole, but the illustration would display a snake completely wrapped around a pole. The diagrams were designed to be supportive rather than essential (i.e., the task could be solved without looking at them). This is common in math curricula, and it allowed for the problems to still be solvable in conditions where the visuals were purely decorative. All four of the tasks a student was assigned had the same visual condition.

Measures. All measures were completed on a computer through the Reasoning Mind curriculum. The first outcome measure was student performance on the intervention tasks described in Materials. Student performance was measured with a simple correct or incorrect $(0 / 1)$ for each problem within the task. Problems are defined as cells that the student had to fill in while solving the problem scenario that were evaluated by the system for mathematical correctness (5-6 problems per task). The correct/incorrects were then averaged across all problems to give a final score on each task. The second outcome measure was the score on a brief post-intervention quiz immediately after the two intervention units (Lessons 88 and 89) that was used as a measure of learning (see Appendix for items). These items were scored 0 if incorrect and 1 if correct (for the entire task). Data were also available for students' response to the prompt "How much did you like this lesson?" on a 5-point scale (Terrible, Bad, OK, Good, Great) for Lessons 88 and 89. Prior knowledge was assessed through performance on the previous unit test and previous lesson tasks (Lesson 87) as controls.

Data Analysis. Data were analyzed using linear regression models that predicted 
accuracy on each of the intervention tasks (compiled across the various problems, with one problem consisting of one prompt the learner typed a numerical response into) and percentage of problems correct on the post-intervention quiz. Predictors included Condition (number of levels depending on the hypothesis being tested), as well as controls for prior knowledge (previous unit test and previous lesson performance). Models were fit using the lmer() package (Bates \& Machler, 2010) in the R software environment.

\section{Experiment 1: Results}

The performance on the intervention tasks (averaged) was examined (see Figure 3 for adjusted means and standard errors by condition). The diagrams hypothesis was tested by comparing diagrammatic illustrations to all other conditions. As can be seen in Table 2, problemsolving accuracy was not better for problems with diagrammatic illustrations (noted as "ref." because it was the reference condition) compared to other conditions. Therefore, the diagram hypothesis was not supported by the findings.

The irrelevance hypothesis (irrelevant illustrations - either decorative or misleadingwould interfere with problem-solving performance) was tested by grouping the decorative illustration and misleading illustration conditions together and comparing to the other three conditions. Problem-solving accuracy was not affected by the presence of irrelevant illustrations, $B=-1.65, \mathrm{SE}=2.2, t=.78, p=.44$ (previous unit test and previous lesson performance were positive predictors, $B=.10, \mathrm{SE}=.04, t=2.4, p=.02 ; B=.74, \mathrm{SE}=.04, t=17.08, p<.001)$. The second part of this hypothesis, that irrelevant illustrations would interfere with later performance on text-only problems, was tested in a similar manner as performance on the intervention tasks with the post-intervention quiz was the dependent variable (see Figure 4 for adjusted means and standard errors by condition). Performance on the post-intervention quiz was not affected by the 
presence of irrelevant illustrations in the lessons, $B=-.56$, $\mathrm{SE}=4.65, t=-.12, p=.90$ (previous unit test and previous lesson performance were again positive predictors, $B=.46, \mathrm{SE}=.09, t=$ $5.08, p<.001 ; B=.20, \mathrm{SE}=.09, t=2.07, p=.04)$. Therefore, the irrelevance hypothesis was not supported by the findings.

The text alone hypothesis was that no illustrations with the intervention tasks would be better for performance on the post intervention quiz. This was tested by comparing the no illustration condition to the other conditions grouped together. As can be seen in Table 3, the no illustration condition performed significantly better than the contextual illustration condition and marginally better than the diagrammatic illustration condition. This provided partial support for the text-alone hypothesis.

The illustrations and interest hypothesis was that students would have more positive attitudes towards lessons with illustrations (of any type) than text alone. Students' interest ratings on the two lessons were averaged, and entered into a linear regression model predicting average lesson rating based on Condition (with the four illustration conditions in one group) as well as their ratings of the four prior lessons as controls (see Figure 5 for adjusted means and standard errors by condition). Data for 49 students was missing due to the student not answering the prompt for either of the lessons. Students who received illustrations did not differ in their ratings of how much they liked the lessons compared to students who did not have illustrations, $B=$ $.08, \mathrm{SE}=.17, t=-.5, p=.62$. Prior lesson rating was a positive predictor, $B=.79, \mathrm{SE}=.05, t=$ $16.51, p<.001$. Therefore, the illustrations and interest hypothesis was not supported by the findings. We now move to a discussion of our second experiment on the interest enhancements of personalization and choice.

\section{Experiment 2: Personalization \& Choice}


Procedure. A survey assessing student interest in each of the topic areas (sports, shopping, video games, or food) was given one month prior to the intervention lesson. Students were asked to rate their level of interest in each topic (0-It's boring, 1-It's okay, 2-I like it, 3-It's my favorite thing), describe how many hours per day they spend on the topic (0-30 minutes, 30 minutes-1 hour, 1-2 hours, 2 hours or more), and rate how much they know about the topic (0almost nothing, 1-a little, 2-a good bit, 3-a whole lot) on 4-point scales. Problems were chosen for students in the survey personalization condition (Condition 2) based on the topic they said they had the highest level of interest in. If a student rated two topics as equally interesting, the topic they reported spending more time each day on was chosen.

Experiment 2 involved two tasks involving rates in Lesson 103 of the Reasoning Mind curriculum (Figure 6). Students were randomly assigned to one of four conditions: 1) a control condition with the standard tasks already in the unit (control), 2) a condition where the topic of the tasks are assigned based on students' reported interest in the 4 personalized topics (sports, food, shopping, and video games) on an interest survey given to all conditions (survey personalization), 3) a condition where students are randomly assigned to one of the four personalized versions of the tasks (random personalization), and 4) a condition where the student is able to choose the problem topic from the four personalized topics right before working on the tasks (choice personalization).

Depending on the condition the student was assigned to, students were given one of four versions of the same task. In each version, the numbers and questions remained the same, but the topic of the task was changed. The control versions of the tasks are in Figure 6. The other four versions of the tasks were personalized and changed the topic to sports, shopping, video games, or food. For the first task (shallow personalization), the personalization was accomplished by 
simply swapping out the word "books" for another noun - footballs, lollipops, necklaces, and crystals. For the second task (deep personalization), the personalization was deeper as more words were swapped out - each of the locations was replaced with a setting that someone who engaged in the personalized topic would be interested in. For example, the video game variation discussed someone traveling to an Enchanted Forest, Dragon Cave, and Wizard's Tower while playing a video game. The syntax of the task was kept the same across conditions given how this is known to affect the readability of mathematics problems (Walkington et al., 2015).

Measures. To assess prior knowledge, we used two measures of student mathematical knowledge. First, we controlled for students' accuracy in the "Guided Study" section of Reasoning Mind over the course of the school year. Guided Study is the main study mode in Reasoning Mind. This mode contains the warm-up, presentation of new concepts and ideas, and practice on novel problems. Second, we controlled for students' average level of performance in the lesson prior to the intervention lesson.

As with Experiment 1, problem-solving performance on each of the problems within each task described in Materials was examined. The first task contained 4 problems, while the second task contained 3 problems. The post measure was a unit test available in the software (see Appendix for items). As with Experiment 1, all measures were completed on a computer through Reasoning Mind.

Data analysis. Data were analyzed using mixed effects linear regression models that predicted: percentage of problems correct on intervention task 1, percentage of problems correct on intervention task 2 , and percentage of problems correct on the posttest. The two intervention tasks were examined separately because the depth of personalization differed (shallow for task 1 , deep for task 2). Predictors included Condition (number of levels depending on hypothesis 
tested), Guided Study Accuracy, and mean percent performance in the previous Reasoning Mind lesson.

\section{Experiment 2: Results}

We examined the intervention tasks separately to test the depth hypothesis (that personalization would have more of an effect when deep rather than shallow). On the first task (shallow personalization), there were no performance differences between the control condition and any of the personalization conditions (see regression tables on Table 4; Figure 7 for adjusted means and standard errors by condition). On the second task (deep personalization), the same analyses were conducted (see regression tables on Table 5; Figure 8 for adjusted means and standard errors by condition). As can be noted on Table 5, choice personalization and survey personalization had higher levels of problem-solving accuracy than did the control. This benefit of deep, but not shallow personalization supports the depth hypothesis.

The ownership hypothesis (that choice personalization would be more effective than the other conditions) was tested by comparing the choice personalization condition to the other conditions on problem-solving performance on the deep personalization task (the shallow personalization task was not examined based on the depth hypothesis analyses) and the posttest. As can be noted on Table 6, problem-solving performance in the choice personalization condition was significantly better than the control condition, but there were no differences between choice personalization and the survey or random personalization conditions. For the posttest, performance in the choice personalization condition was significantly better than the random personalization condition, but there were no differences between choice personalization and the survey or control conditions (see Table 7 for regression statistics; see Figure 9 for adjusted means and standard errors by condition). Thus we find some limited support for the 
ownership hypothesis.

The grain size hypothesis, that smaller grain size would yield better performance, was tested by comparing the smaller grain size conditions (choice and survey personalization) and the broader grain size conditions (random personalization and control). For the deep personalization task, the smaller grain size conditions had better problem-solving performance than the broader grain size condition, $B=6.89, \mathrm{SE}=2.96, t=2.33, p=.02$. However, this did not carry over to better performance on the posttest, $B=4.84, \mathrm{SE}=4.24, t=1.14, p=.25$. Thus we find support for the grain size hypothesis only for immediate performance, and not for longer-term learning.

In the no personalization hypothesis, the control condition was expected to outperform each of the other three conditions on a non-personalized later assessment. As can be seen in the regression statistics in Table 8, the control condition did not perform reliably better than any other condition (see Figure 9 for adjusted means and standard errors by condition). Thus we do not find support for the no personalization hypthoesis.

\section{Discussion}

In two experiments, a variety of interest-enhancing curriculum design methods for story problems were examined. In the first experiment, four different types of visuals (decorative illustrations, contextual illustrations, misleading illustrations, and diagrammatic illustrations) as well as text alone were examined for their effects on problem-solving performance, learning, and attitudes towards the lesson. In the second experiment, variations in personalization in terms of depth, grain size, and ownership were examined for their effects on problem-solving performance as well as learning. In the following sections, we discuss the hypotheses for each of these experiments and whether or not the findings support these hypotheses.

\section{Visual Representations}


Illustrations are often used as an interest-enhancement approach in curriculum design (Magner et al., 2014). The implications on problem-solving performance and learning of multiple types of illustrations were tested. We examined diagrammatic illustrations as a potential means of supporting problem solving. Diagrammatic illustrations were expected to yield better performance on intervention problems compared to the other conditions (diagram hypothesis). The presence of mathematical information in visual format was expected to complement the verbal information, thereby it was thought this would help students to understand the story problem as a whole (Mayer, 2017; Schnotz, 2002), which could also make the problem more interesting and engaging (Connelly, 2011; Magner et al. 2016). However, the findings indicated that problem-solving performance was not better if accompanied by a diagrammatic illustration compared to the other conditions. One reason for this could be that, because the diagram was illustrated, it was not perceived as mathematically useful or relevant, similar to findings on contextual illustrations (see Dewolf, 2014).

According to the coherence principle (Clark \& Mayer, 2016), visuals that are irrelevant to the story problems would interfere with learning because such visuals are unnecessary information to process. Therefore, we expected student whose story problems had irrelevant visuals (decorative and misleading illustrations) to perform less well than students with story problems in other visual conditions (irrelevance hypothesis). However, the findings indicated that these irrelevant visuals did not interfere with either performance on the intervention problems or the later assessment of learning from the intervention problems. This finding is consistent with previous findings that similar types of visuals did not appear to influence middle school students learning from a mathematics lesson (Clinton et al., 2017). One reason these irrelevant illustrations did not appear to distract from the story problem could be that these types 
of visuals are quite common in mathematics materials (Clinton \& Cooper, 2015; Mayer et al., 1995) and students may be used to seeing them. Alternatively, it is possible that the design of the irrelevant illustrations in this study were not distracting enough to cause detriments to learning. In previous work on how the seductive details effect interfered with learning, the irrelevant visuals had to do with life-threatening issues (Harp \& Mayer, 1998), the irrelevant visuals were purposefully placed to be noticed by the participants (Chang \& Choi, 2014), or there were multiple distracting visuals (Sanchez \& Wiley, 2006).

One concern about the use of supports such as visuals during the learning process is that students may become reliant upon them and have difficulty when assessed without these visuals. In this way, only having text while learning the mathematics could be a desirable difficulty that would promote student learning long term (Bjork, 2018). On the assessment of learning, students who had no illustrations (text alone) with their story problems performed better than students who had contextual illustrations with their story problems, providing some support for the text alone hypothesis. It is possible that students who only had text for their story problems outperformed those who had contextual illustrations because the text alone provided a desirable difficulty. However, there were no differences between text alone and the other types of illustrations on the assessment of later learning.

Although the illustrations were intended to enhance student attitudes towards the problems, there was no evidence to support the illustrations and interest hypothesis in which the illustrations yielded better attitudes towards the lessons than did only text. These findings conflict with other findings in which materials with colorful and vivid pictures were considered more interesting than the materials without these images (e.g., Cooper et al., 2018; Durik \& Harackiewicz, 2007). One reason could be that there was only one item to gauge student 
attitudes for each lesson and that did not provide sufficient precision to detect an effect. Another could be that the visuals were not integrated into the problem enough for students to notice and be affected by them in their overall performance, learning, or attitudes (Hoogland, Pepin, de Koning, Bakker, \& Gravemeijer, 2018). In other words, these illustrations did not actually enhance interest despite that being the intention in curriculum design.

\section{Personalization}

The curriculum design approach through enhancing interest by personalizing problems to students' interests was examined in Experiment 2. The two intervention tasks in Experiment 2 varied in the depth of personalization to examine the depth hypothesis that a personalization would have more of an effect if done in a deep rather than shallow manner. The findings indicated support for the depth hypothesis. Personalization had no effect on a shallow level, but students in two of the personalization conditions (choice and survey) did better on solving the problems that were part of the deep intervention task.

The ownership hypothesis was that students who got to choose which topic their task would be on (choice personalization) would perform better on solving that task than would students in other conditions. This hypothesis was somewhat supported in that the choice personalization benefited problem-solving performance for the deep personalization task compared to the control condition, but not the two other personalization conditions (random or survey). For the learning assessment, students who got to choose their personalized tasks did better than students who were randomly assigned a topic. These findings indicate that having a sense of choice and ownership may have fostered understanding of and learning from the story problems, which is consistent with other findings (Høgheim \& Reber, 2015). Students who got to choose their topic may have found the story problems more personally meaningful and 
subsequently engaged more deeply in the lesson (see Priniski, Hecht, \& Harackiewicz, 2018, for discussion).

The grain size hypothesis in which narrow topics were expected to promote more engagement and subsequently have better performance than broad topics was partially supported by the findings. Personalization with a survey and with choice had the smallest grain size, as tasks were selected to be relevant to individual learners' interests. On the other hand, the control condition and random personalization conditions had larger grain sizes, as the tasks were simply written to be understandable contexts for sixth grade students. On the deep personalization task, students with problems in the survey and choice personalization conditions (narrow grain size) outperformed those in the control or random personalization conditions (broad grain size), indicating that a combination of grain size and depth may be optimal for problem-solving performance (see Walkington \& Hayata, 2017, for discussion). However, these findings did not carry over to the learning assessment. This could be because the benefits of personalization at a fine grain size may involve extra information to process which could offset some of the benefits for learning (Walkington \& Hayata, 2017).

As with the illustrations experiment, we addressed the possibility that personalization could inadvertently weaken learning because of desirable difficulties (Richland, Bhork, Finley, \& Linn, 2005). However, the findings indicated no support for the no personalization hypothesis on the assessment of learning, which is consistent with other findings that scaffolds that facilitate understanding and enhance interest do not necessarily impede long-term learning (Beitzel \& Staley, 2015; Marsh \& Sink, 2010).

\section{Limitations and Future Directions}


There were a number of limitations to these experiments that should be noted. Desirable difficulties was considered a factor in both experiments, however we were not able to get effort or difficulty ratings, which would be informative as to whether the different types of visuals or personalization actually made the lesson seem easier. Future work using effort ratings in a manner similar to a study of computer-based dynamic visualizations and desirable difficulty would allow for a direct test of this issue (Wichmann \& Timpe, 2015).

Individual differences in terms of working memory capacity, mathematics skill, and interest in mathematics have been noted as important in previous research on visuals and personalization, but were not considered in this study. This is an important area for future research. Adaptive environments for K-12 learning have enormous potential to transform education by catering to individual student knowledge and preferences. As we confront a new, digital age where instruction is inexorably linked to online curricular systems, understanding the optimal way to adapt to students' characteristics will become increasingly important.

Finally, attitudinal measures were not available in for the personalization experiment, which limits the interpretation of findings. It would be useful in future work to examine how different approaches to personalization affects student attitudes towards lessons. Such examinations would further illuminate how depth, grain size, and ownership in personalization affect students' experiences with learning mathematics.

\section{Implications and Conclusions}

Taken together, the results suggest that curriculum designers need to think critically when considering interest-enhancing interventions. Our findings indicate that illustrations of various types alongside story problems do not affect performance on these problems and may actually interfere with performance on later learning assessments without illustrations. In contrast, the 
personalization findings suggest that the addition of interest-based content is not particularly seductive or distracting, and that it may help if it is well-matched to learners' actual preferences. However, the depth of the personalization and how personalized problems are assigned to students are important. This suggests that when compiling data from multiple studies on interestbased enhancements, it is critical to pay close attention to how the enhancement was actually implemented in the curriculum.

Students' interest in learning mathematics can wane over the middle grades, and curriculum designers are increasingly drawn towards quick solutions to attempt increase student engagement with their materials. Many of these solutions can involve considerable cost to the curriculum developer (e.g., hiring an artist or writing multiple versions of each problem), thus it is important to consider how motivational enhancements impact students' understanding of mathematical ideas. Future research should delineate the most effective interest-enhancing supports for different profiles of learners, and for different mathematical content areas. 


\section{References}

Ainley, M., Hidi, S., \& Berndorff, D. (2002). Interest, learning, and the psychological processes that mediate their relationship. Journal of Educational Psychology, 94(3), 545. doi: $10.1037 / 0022-0663.94 .3 .545$

Anand, P., \& Ross, S. (1987). Using computer-assisted instruction to personalize arithmetic materials for elementary school children. Journal of Educational Psychology, 79(1), 72 78. doi: $10.1037 / 0022-0663.79 .1 .72$

Bates, D., \& Maechler, M. (2010). lme4: Linear mixed-effects models using S4 classes. R package version 0.999375-35. http://CRAN.R-project.org/package=lme4

Bates, E. T., \& Wiest, L. R. (2004). Impact of personalization of mathematical word problems on student performance. The Mathematics Educator, 14(2), 17-26. Retrieved from http://tme.journals.libs.uga.edu/index.php/tme/article/view/146/135

Beitzel, B. D., \& Staley, R. K. (2015). The efficacy of using diagrams when solving probability word problems in college. The Journal of Experimental Education, 83(1), 130-145. doi: $10.1080 / 00220973.2013 .876232$

Berends, I. E., \& van Lieshout, E. C. (2009). The effect of illustrations in arithmetic problemsolving: Effects of increased cognitive load. Learning and Instruction, 19(4), 345-353. doi: 10.1016/j.learninstruc.2008.06.012

Bernacki, M., \& Walkington, C. (2018). The Role of Situational Interest in Personalized Learning. Journal of Educational Psychology, 110(6), 864-881. DOI: $10.1037 / \mathrm{edu} 0000250$ 
Bjork, R. A. (2018). Being suspicious of the sense of ease and undeterred by the sense of difficulty: Looking back at Schmidt and Bjork (1992). Perspectives on Psychological Science, 13(2), 146-148. Doi: 10.1177/1745691617690642

Boonen, A. J., van Wesel, F., Jolles, J., \& van der Schoot, M. (2014). The role of visual representation type, spatial ability, and reading comprehension in word problem solving: An item-level analysis in elementary school children. International Journal of Educational Research, 68, 15-26. doi: 10.1016/j.ijer.2014.08.001

Booth, J. L., \& Koedinger, K. R. (2012). Are diagrams always helpful tools? Developmental and individual differences in the effect of presentation format on student problem solving. British Journal of Educational Psychology, 82(3), 492-511. doi: 10.1111/j.20448279.2011.02041.x

Boriack, A.W., Stillisano, J.R., Wright, K.B., \& Waxman, H.C. (2015). Independent evaluation of Reasoning Mind programing. Retrieved from https://www.reasoningmind.org/rmwp/wp-content/uploads/2016/03/Texas-AMIndependent-Evaluation-of-Reasoning-Mind-Programming.pdf

Caker, O., \& Simsek, N. (2010). A comparative analysis of computer and paper-based personalization on student achievement. Computers \& Education, 55, 1524-1531. doi: 10.1016/j.compedu.2010.06.018

Clark, R. C., \& Mayer, R. E. (2016). E-learning and the science of instruction: Proven guidelines for consumers and designers of multimedia learning. John Wiley \& Sons.

Clinton, V. (2015). Examining associations between reading motivation and inference generation beyond reading comprehension skill. Reading Psychology, 36(6), 473-498. doi: $10.1080 / 02702711.2014 .892040$ 
Clinton, V., Alibali, M.W., \& Nathan, M.J. (2016). Learning about posterior probability: Do diagrams and elaborative interrogations help? Journal of Experimental Education, 84, 579-599. doi: 10.1080/00220973.2015.1048847

Clinton, V. \& Cooper, J.L. (2015, April). Teacher viewpoints of instructional design principles for visuals in a middle school math curriculum. Paper presented at the Annual Meeting of the American Educational Research Association Annual Meeting, Chicago, IL.

Clinton, V. \& van den Broek, P. (2012). Interest, inferences, and learning from texts. Learning and Individual Differences, 22(6), 650-663. doi: 10.1016/j.lindif.2012.07.004

Clinton, V., Cooper, J.L., Michaelis, J., Alibali, M.W., \& Nathan, M.J. (2017). Revising visuals based on instructional design principles: Effects on cognitive load and learning. In C. Was, F.J. Sansosti, \& B.J. Morris (Eds.) Eye-tracking technology applications in educational research, (pp. 195-218). Hershey, PA: IGI Global.

Chang, Y., \& Choi, S. (2014). Effects of seductive details evidenced by gaze duration. Neurobiology of Learning and Memory, 109, 131-138. doi: 10.1016/j.nlm.2014.01.005

Common Core Standards for Mathematical Practice 2015. retrieved from http://www.corestandards.org/Math/

Connelly, D. A. (2011). Applying Silvia's model of interest to academic text: Is there a third appraisal? Learning and Individual Differences, 21(5), 624-628. doi: 10.1016/j.lindif.2011.04.007

Cooper, J. L., Sidney, P. G., \& Alibali, M. W. (2018). Who Benefits from Diagrams and Illustrations in Math Problems? Ability and Attitudes Matter. Applied Cognitive Psychology, 32(1), 24-38. Doi: 10.1002/acp.3371 
Cordova, D., \& Lepper, M. (1996). Intrinsic motivation and the process of learning: Beneficial effects of contextualization, personalization, and choice. Journal of Educational Psychology, 88(4), 715-730. doi: 10.1037//0022-0663.88.4.715

Davis-Dorsey, J., Ross, S., and Morrison, G. (1991). The role of rewording and context personalization in the solving of mathematical word problems. Journal of Educational Psychology, 83(1), 61-68. doi: 10.1037//0022-0663.83.1.61

Deieso, D., \& Fraser, B. J. (in press). Learning environment, attitudes and anxiety across the transition from primary to secondary school mathematics. Learning Environments Research. doi: 10.1007/s10984-018-9261-5

Dewolf, T. (2014). Get the picture? Are representational illustrations effective in helping pupils to solve mathematically word problems realistically? Unpublished doctoral dissertation. University of Leuven.

Dewolf, T., van Dooren, W., Ev Cimen, E., \& Verschaffel, L. (2014). The impact of illustrations and warnings on solving mathematical word problems realistically. The Journal of Experimental Education, 82, 103-120. doi: 10.1080/00220973.2012.745468

Durik, A., \& Harackiewicz, J. (2007). Different strokes for different folks: How individual interest moderates effects of situational factors on task interest. Journal of Educational Psychology, 99(3), 597-610. doi: 10.1037/0022-0663.99.3.597

Flowerday, T., \& Shell, D. F. (2015). Disentangling the effects of interest and choice on learning, engagement, and attitude. Learning and Individual Differences, 40, 134-140. Doi: $10.1016 /$ j.lindif.2015.05.003 
Frenzel, A. C., Goetz, T., Pekrun, R., \& Watt, H. M. G. (2010). Development of mathematics interest in adolescence: Influences of gender, family, and school context. Journal of Researchr on Adolescence, 20, 507-537. doi: 10.1111/j.1532-7795.2010.00645.x

Fyfe, E. R., \& Rittle-Johnson, B. (2017). Mathematics practice without feedback: A desirable difficulty in a classroom setting. Instructional Science, 45(2), 177-194. doi: $10.1007 / \mathrm{s} 11251-016-9401-1$

Goldstone, R. L., \& Son, J. Y. (2005). The transfer of scientific principles using concrete and idealized simulations. The Journal of the Learning Sciences, 14(1), 69-110. doi: $10.1207 / \mathrm{s} 15327809 j 1 \mathrm{l} 1401 \_4$

Harackiewicz, J. M., Durik, A. M., Barron, K. E., Linnenbrink-Garcia, L., \& Tauer, J. M. (2008). The role of achievement goals in the development of interest: Reciprocal relations between achievement goals, interest, and performance. Journal of Educational Psychology, 100(1), 105. Doi: 10.1037/0022-0663.100.1.105

Harackiewicz, J. M., Smith, J. L., \& Priniski, S. J. (2016). Interest matters: The importance of promoting interest in education. Policy Insights from the Behavioral and Brain Sciences, 3(2), 220-227. doi: 10.1177/2372732216655542

Harp, S. F., \& Mayer, R. E. (1998). How seductive details do their damage: A theory of cognitive interest in science learning. Journal of Educational Psychology, 90(3), 414434. doi: 10.1037/0022-0663.90.3.414

Harp, S. F., \& Mayer, R. E. (1997). The role of interest in learning from scientific text and illustrations: On the distinction between emotional interest and cognitive interest. Journal of Educational Psychology, 89(1), 92. doi: 10.1037/0022-0663.89.1.92 
Heddy, B. C., Sinatra, G. M., Seli, H., Taasoobshirazi, G., \& Mukhopadhyay, A. (2017). Making learning meaningful: facilitating interest development and transfer in at-risk college students. Educational Psychology, 37(5), 565-581. Doi:

$10.1080 / 01443410.2016 .1150420$

Hidi, S. E., \& Ainley, M. (2008). Interest and self-regulation: Relationships between two variables that influence learning. In D. H. Schunk \& B. J. Zimmerman (Eds.), Motivation and self-regulated learning: Theory, research, and applications (pp. 77-109). New York: Taylor \& Francis.

Hidi, S., \& Renninger, K. (2006). The four-phase model of interest development. Educational Psychologist, 41(2), 111-127. doi: 10.1207/s15326985ep4102_4

Høgheim, S., \& Reber, R. (2015). Supporting interest of middle school students in mathematics through context personalization and example choice. Contemporary Educational Psychology, 42, 17-25. doi: 10.1016/j.cedpsych.2015.03.006

Hoogland, K., Pepin, B., de Koning, J., Bakker, A., \& Gravemeijer, K. (2018). Word problems versus image-rich problems: an analysis of effects of task characteristics on students' performance on contextual mathematics problems. Research in Mathematics Education, 20, 1-16. Doi: 10.1080/14794802.2017.1413414

Hulleman, C. S., \& Harackiewicz, J. M. (2009). Promoting interest and performance in high school science classes. Science, 326(5958), 1410-1412. doi: 10.1126/science.1177067

Jaeger, A. J., \& Wiley, J. (2014). Do illustrations help or harm metacomprehension accuracy? Learning and Instruction, 34, 58-73. doi: 10.1016/j.learninstruc.2014.08.002

Jitendra, A. K., \& Star, J. R. (2012). An exploratory study contrasting high-and low-achieving students' percent word problem solving. Learning and Individual Differences, 22(1), 151- 
158. doi: 10.1016/j.lindif.2011.11.003

Kajander, A. \& Lovric, M. (2009) Mathematics textbooks and their potential role in supporting misconceptions. International Journal of Mathematical Education in Science and Technology, 40(2), 173-181, doi: 10.1080/00207390701691558

Kim, S., Jiang, Y., \& Song, J. (2015). The effects of interest and utility value on mathematics engagement and achievement. In K. A. Renninger, M. Nieswandt, \& S. Hidi (Eds.), Interest in mathematics and science learning (pp. 63-78). Washington, DC: American Educational Research Association.

Koedinger, K., Alibali, M., \& Nathan, M. (2008). Trade-offs between grounded and abstract representations: Evidence from algebra problem solving. Cognitive Science, 32, 366-397. doi: $10.1080 / 03640210701863933$

Ku, H., \& Sullivan, H. (2000). Personalization of mathematics word problems in Taiwan. Educational Technology Research and Development, 48(3), 49-59. doi: $10.1007 / \mathrm{bf} 02319857$

Lindner, M. A., Ihme, J. M., Saß, S., \& Köller, O. (2016). How representational pictures enhance students' performance and test-taking pleasure in low-stakes assessment. European Journal of Psychological Assessment. doi: 10.1027/1015-5759/a000351

Linnenbrink-Garcia, L., Durik, A. M., Conley, A. M., Barron, K. E., Tauer, J. M., Karabenick, S. A., \& Harackiewicz, J. M. (2010). Measuring situational interest in academic domains. Educational and Psychological Measurement, 70(4), 647-671 doi:

$10.1177 / 0013164409355699$ 
Linnenbrink-Garcia, L., Patall, E. A., \& Messersmith, E. E. (2013). Antecedents and consequences of situational interest. British Journal of Educational Psychology, 83(4), 591-614. doi: 10.1111/j.2044-8279.2012.02080.x

Lehman, S., Schraw, G., McCrudden, M. T., \& Hartley, K. (2007). Processing recall of seductive details in scientific text. Contemporary Educational Psychology, 32(4), 569-587. doi: 10.1016/j.cedpsych.2006.07.002

Lopez, C. \& Sullivan, H. (1992). Effects of personalization of instructional context on the achievement and attitudes of Hispanic students. Educational Technology Research and Development, 40(4), 5-13. doi: 10.1007/bf02296895

Magner, U. I. E., Glogger, I., \& Renkl, A. (2016). Which features make illustrations in multimedia learning interesting?. Educational Psychology, 36(9), 1596-1613. doi: $10.1080 / 01443410.2014 .933177$

Magner, U. I., Schwonke, R., Aleven, V., Popescu, O., \& Renkl, A. (2014). Triggering situational interest by decorative illustrations both fosters and hinders learning in computer-based learning environments. Learning and instruction, 29, 141-152. doi: 10.1016/j.learninstruc.2012.07.002

Marsh, E. J., \& Sink, H. E. (2010). Access to handouts of presentation slides during lecture: Consequences for learning. Applied Cognitive Psychology, 24(5), 691-706. doi: 10.1002/acp.1579

Mayer, R. E. (2014a). Incorporating motivation into multimedia learning. Learning and Instruction, 29, 171-173. doi: 10.1016/j.learninstruc.2013.04.003 
Mayer, R. E. (2014b). Cognitive theory of multimedia learning. In R. E. Mayer (Ed.), Cambridge Handbook of Multimedia Learning (2nd ed., pp. 43-71). New York: Cambridge University Press. http://dx.doi.org/10.1017/cbo9781139547369.005

Mayer, R. E., Sims, V., \& Tajika, H. (1995). Brief note: A comparison of how textbooks teach mathematical problem solving in Japan and the United States. American Educational Research Journal, 32(2), 443-460. Doi: 10.3102/00028312032002443

McCoy L. P. (2005). Effect of demographic and personal variables on achievement in eighthgrade algebra. Journal of Educational Research, 98(3), 131-135. doi: 10.3200/joer.98.3.131-135

McDaniel, M. A., \& Butler, A. C. (2010). A contextual framework for understanding when difficulties are desirable. In A. S. Benjamin (Ed.), Successful remembering and successful forgetting: A festschrift in honor of Robert A. Bjork (pp. 175-198). New York, NY:

Psychology Press.

McNeil, N. M., Uttal, D. H., Jarvin, L., \& Sternberg, R. J. (2009). Should you show me the money? Concrete objects both hurt and help performance on mathematics problems. Learning and Instruction, 19(2), 171-184. Doi: 10.1016/j.learninstruc.2008.03.005

Miele, D. B., \& Wigfield, A. (2014). Quantitative and qualitative relations between motivation and critical-analytic thinking. Educational Psychology Review, 26(4), 519-541. doi: $10.1007 / \mathrm{s} 10648-014-9282-2$

Mitchell, M. (1993). Situational interest: Its multifaceted structure in the secondary school mathematics classroom. Journal of Educational Psychology, 85, 424-436. 10.1037/00220663.85 .3 .424 
Park, B., Flowerday, T., \& Brünken, R. (2015). Cognitive and affective effects of seductive details in multimedia learning. Computers in Human Behavior, 44, 267-278. http://dx.doi.org/10.1016/j.chb.2014.10.061

Patall, E. A. (2013). Constructing motivation through choice, interest, and interestingness. Journal of Educational Psychology, 105(2), 522-534. doi: 10.1037/a0030307

Peeters, D., Snijders, T. M., Hagoort, P., \& Özyürek, A. (2017). Linking language to the visual world: Neural correlates of comprehending verbal reference to objects through pointing and visual cues. Neuropsychologia, 95, 21-29. Doi:

10.1016/j.neuropsychologia.2016.12.004

Petersen, L. A., \& McNeil, N. M. (2013). Effects of perceptually rich manipulatives on preschoolers' counting performance: Established knowledge counts. Child Development, 84(3), 1020-1033. Doi: 10.1111/cdev.12028

Pike, M. M., Barnes, M. A., \& Barron, R. W. (2010). The role of illustrations in children's inferential comprehension. Journal of Experimental Child Psychology, 105(3), 243-255. doi: 10.1016/j.jecp.2009.10.006

Potvin, P., \& Hasni, A. (2014). Interest, motivation and attitude towards science and technology at K-12 levels: A systematic review of 12 years of educational research. Studies in Science Education, 50(1), 85-129. doi: 10.1080/03057267.2014.881626

Priniski, S. J., Hecht, C. A., \& Harackiewicz, J. M. (2018). Making learning personally meaningful: A new framework for relevance research. The Journal of Experimental Education, 86(1), 11-29. doi: 10.1080/00220973.2017.1380589 
Reber, R., Hetland, H., Chen, W., Norman, E., \& Kobbeltvedt, T. (2009). Effects of example choice on interest, control, and learning. Journal of the Learning Sciences, 18, 509-548. doi: $10.1080 / 10508400903191896$

Rey, G. D. (2012). A review of research and a meta-analysis of the seductive detail effect. Educational Research Review, 7(3), 216-237. doi: 10.1016/j.edurev.2012.05.003

Richland, L. E., Bjork, R. A., Finley, J. R., \& Linn, M. C. (2005). Linking cognitive science to education: Generation and interleaving effects. In B. G. Bara, L. Barsalou, \& M. Bucciarelli (Eds.), Proceedings of the 27th Annual Conference of the Cognitive Science Society (pp. 1850-1855). Mahwah, NJ: Erlbaum.

Rotgans, J. I., \& Schmidt, H. G. (2017). Interest development: Arousing situational interest affects the growth trajectory of individual interest. Contemporary Educational Psychology, 49, 175-184. doi: 10.1016/j.cedpsych.2017.02.003

Sanchez, C. A., \& Wiley, J. (2006). An examination of the seductive details effect in terms of working memory capacity. Memory \& Cognition, 34(2), 344-355. http://dx.doi.org/10.3758/BF03193412

Saß, S., Wittwer, J., Senkbeil, M., \& Köller, O. (2012). Pictures in test items: Effects on response time and response correctness. Applied Cognitive Psychology, 26(1), 70-81. doi: 10.1002/acp.1798

Schiefele, U., \& Krapp, A. (1996). Topic interest and free recall of expository text. Learning and Individual Differences, 8(2), 141-160. doi: 10.1016/s1041-6080(96)90030-8

Schmidt, R. A., \& Bjork, R. A. (1992). New conceptualizations of practice: Common principles in three paradigms suggest new concepts for training. Psychological Science, 3(4), $207-$ 217. doi: 10.1111/j.1467-9280.1992.tb00029.x 
Schneider, S., Nebel, S., \& Rey, G. D. (2016). Decorative pictures and emotional design in multimedia learning. Learning and Instruction, 44, 65-73.

Schnotz, W. (2002). Commentary: Towards an integrated view of learning from text and visual displays. Educational Psychology Review, 14(1), 101-120. http://dx.doi.org/10.1023/A:1013136727916

Schweppe, J., \& Rummer, R. (2016). Integrating written text and graphics as a desirable difficulty in long-term multimedia learning. Computers in Human Behavior, 60, 131-137. doi: $10.1016 /$ j.chb.2016.02.035

Sommet, N., \& Elliot, A. J. (2017). Achievement goals, reasons for goal pursuit, and achievement goal complexes as predictors of beneficial outcomes: Is the influence of goals reducible to reasons?. Journal of Educational Psychology, 109(8), 1141- 1162. doi: 10.1037/edu0000199

Son, J. Y., \& Goldstone, R. L. (2009). Contextualization in perspective. Cognition and Instruction, 27(1), 51-89. Doi: 10.1080/07370000802584539

Walkington, C. (2013). Using adaptive learning technologies to personalize instruction to student interests: The impact of relevant contexts on performance and learning outcomes. Journal of Educational Psychology, 105(4), 932-945. doi: 10.1037/a0031882

Walkington, C., (2017). Design research on personalized problem-posing. In Galindo, E., \& Newton, J., (Eds.) Proceedings of the 39th annual meeting of the North American Chapter of the International Group for the Psychology of Mathematics Education (pp. 195-202). Indianapolis, IN: Hoosier Association of Mathematics Teacher Educators.

Walkington, C., \& Bernacki, M. (2014). Motivating students by “personalizing” learning around individual interests: A consideration of theory, design, and implementation issues. In S. 
Karabenick \& T. Urdan (eds.) Advances in Motivation and Achievement Volume 18 (pp. 139-176), Emerald Group Publishing. doi: 10.1108/s0749-742320140000018004 Walkington, C., \& Bernacki, M. (2015). Students authoring personalized “Algebra Stories”: Problem-posing in the context of out-of-school interests. Journal of Mathematical Behavior, 40B, 171-191. doi: 10.1016/j.jmathb.2015.08.001

Walkington, C., \& Bernacki, M. L. (2018). Personalization of instruction: Design dimensions and implications for cognition. The Journal of Experimental Education, 86(1), 50-68. doi: $10.1080 / 00220973.2017 .1380590$

Walkington, C., \& Bernacki, M. (in-press). Personalizing algebra to students' interests: How student funds of knowledge moderate outcomes. International Journal of Artificial Intelligence in Education. doi: 10.1007/s40593-018-0168-1

Walkington, C., Clinton, V., Ritter, S. N., \& Nathan, M. J. (2015). How readability and topic incidence relate to performance on mathematics story problems in computer-based curricula. Journal of Educational Psychology, 107(4), 1051-1074. doi: 10.1037/edu0000036

Walkington, C., Clinton, V., \& Shivraj, P. (2018). How readability factors are differentially associated with performance for students of different backgrounds when solving math word problems. American Educational Research Journal, 55(2), 362-414. doi: $10.3102 / 0002831217737028$

Walkington, C., Cooper, J., \& Howell, E. (2013). The effects of visual representations and interest-based personalization on solving percent problems. In Martinez, M. \& Castro Superfine, A (Eds.) Proceedings of the 35th annual meeting of the North American 
Chapter of the International Group for the Psychology of Mathematics Education (pp. 533-536). Chicago, IL: University of Illinois at Chicago.

Walkington, C., Cooper, J., Nathan, M.J., \& Alibali, M.A. (November, 2015). The effects of visual representations and interest-based personalization on solving mathematics story problems. Poster presentation at The 37th annual meeting of the North American Chapter of the International Group for the Psychology of Mathematics Education. East Lansing, MI: Michigan State University.

Walkington, C. \& Hayata, C. (2017). Designing Learning Personalized to Students' Interests: Balancing Rich Experiences with Mathematical Goals. ZDM Mathematics Education, 49(4), 519-530. doi: 10.1007/s11858-017-0842-z

Wang, N., Johnson, W. L., Mayer, R. E., Rizzo, P., Shaw, E., and Collins, H. (2008). The politeness effect: Pedagogical agents and learning outcomes. International Journal of Human-Computer Studies, 66. 98-112. Doi: 10.1016/j.ijhcs.2007.09.003

Waxman, H.C. and Houston, W.R. (2012). Evaluation of the 2010-2011 Reasoning Mind Program in Beaumont ISD. Retrieved from: http://www.reasoningmind.org/pdf/Waxman-Houston_Report_2011.pdf

Wichmann, A., \& Timpe, S. (2015). Can Dynamic Visualizations with Variable Control Enhance the Acquisition of Intuitive Knowledge? Journal of Science Education and Technology, 24(5), 709-720. doi: 10.1007/s10956-015-9554-8

Woodward, J., Beckmann, S., Driscoll, M., Franke, M., Herzig, P., Jitendra, A., \& Ogbuehi, P. (2012). Improving Mathematical Problem Solving in Grades 4 through 8. IES Practice Guide. NCEE 2012-4055. What Works Clearinghouse. 


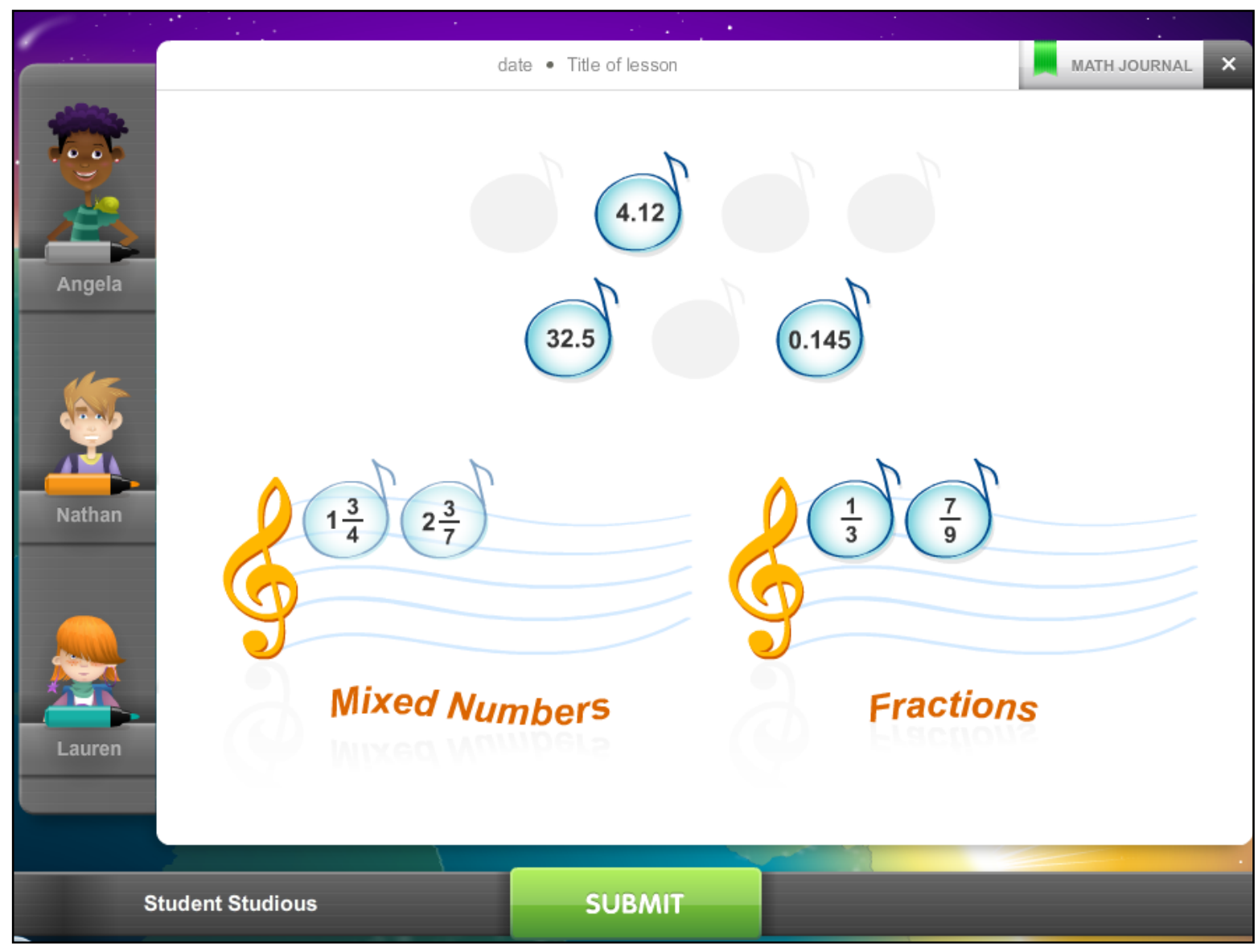

Figure 1. Screen Shot of the Genie 3 platform 


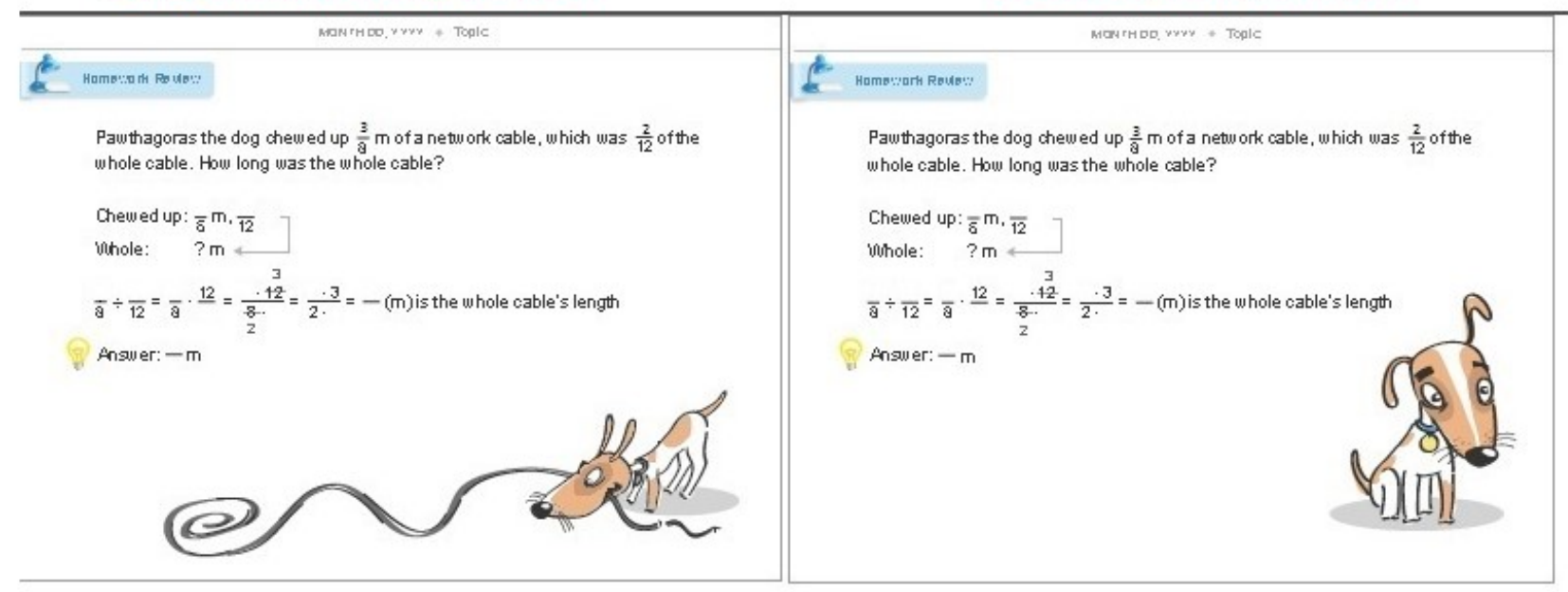

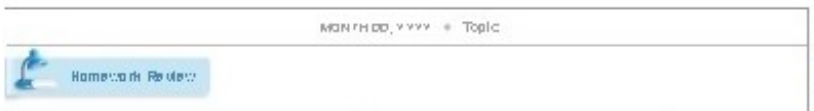

Pawthagoras the dog chewed up $\frac{3}{3}$ m of a network cable, which was $\frac{2}{12}$ of the whole cable. How long was the whole cable?

$$
\begin{aligned}
& \text { Chewed up: } \overline{5} \mathrm{~m} \cdot \overline{12} \\
& \text { Whole: } ? \mathrm{~m} \\
& \overline{\mathrm{a}} \div \frac{\overline{12}}{12}=\frac{-12}{\mathrm{a}} \cdot \frac{12}{\frac{3}{8 \cdot \cdot}}=\frac{\cdot 3}{2 \cdot}=-(\mathrm{m}) \text { is the whole cable's length } \\
& \text { Answer: }-\mathrm{m}
\end{aligned}
$$

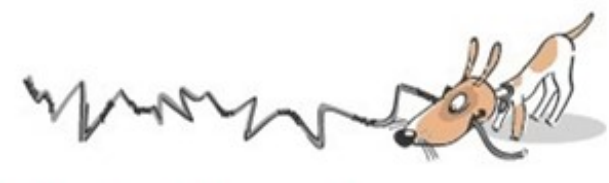

Misleading Illustration

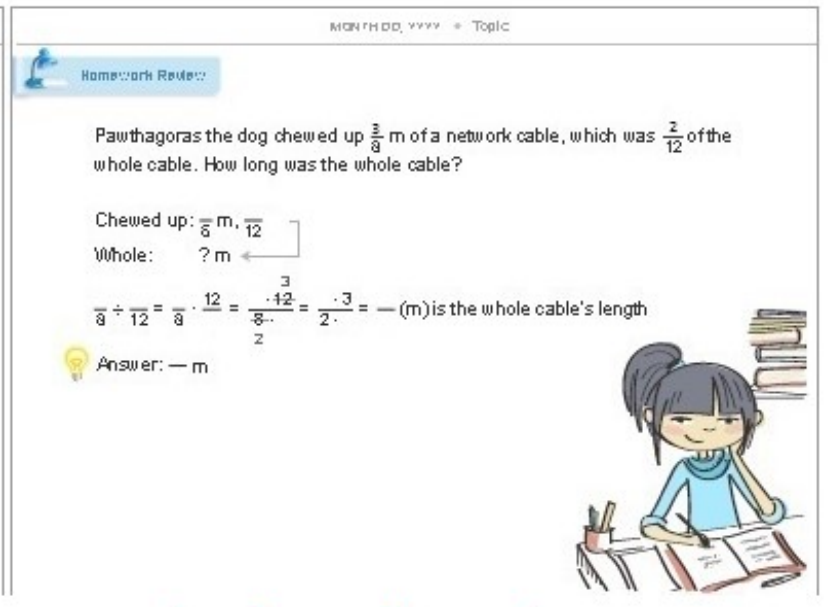

Irrelevant Illustration

Figure 2. Example of conditions in Study 1 (there was also a "No Illustration" condition) 


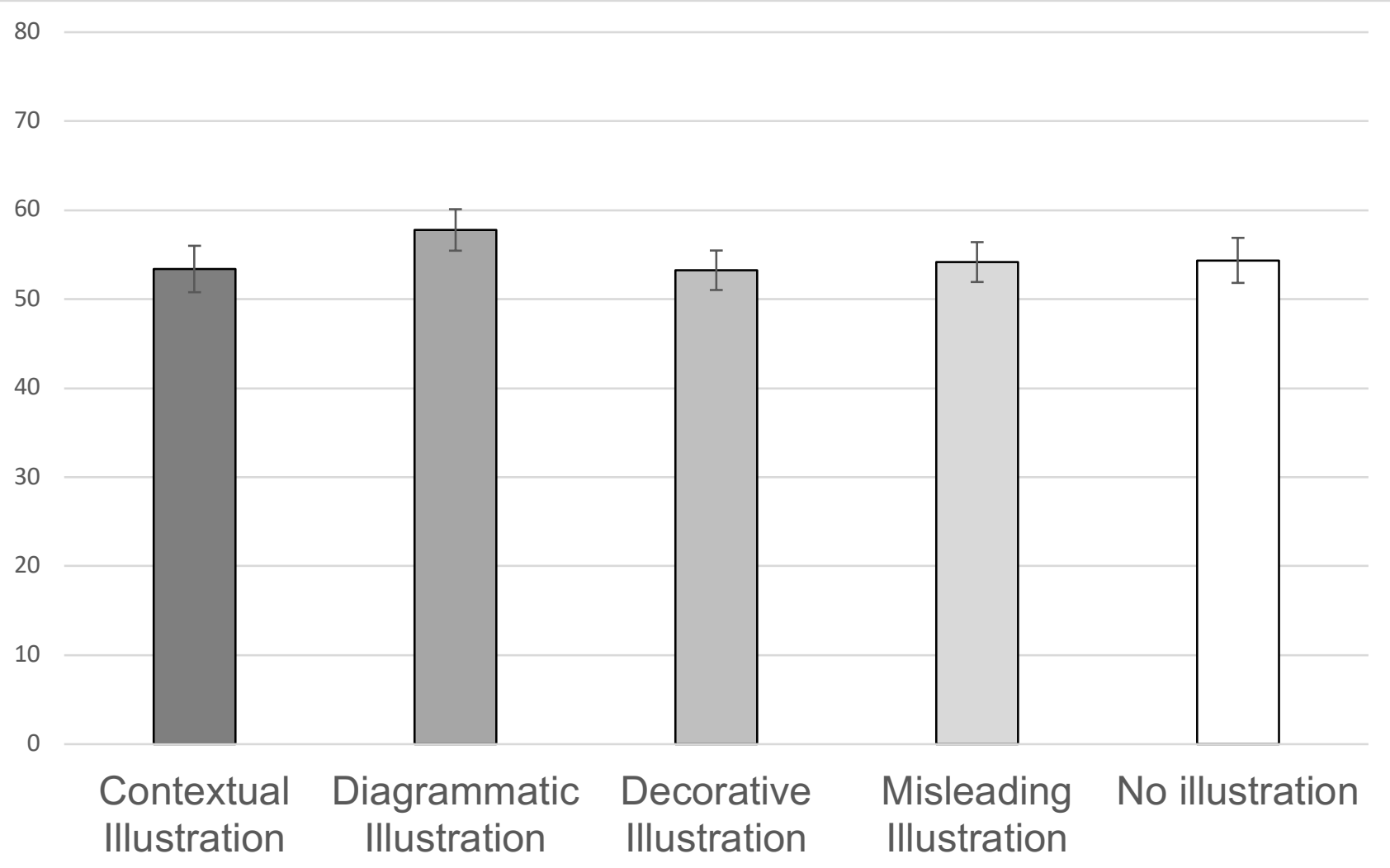

Figure 3. Average problem-solving performance for intervention problems by condition (means and +/- 1 standard error bars adjusted for the covariates of pretest and previous lesson performance) 


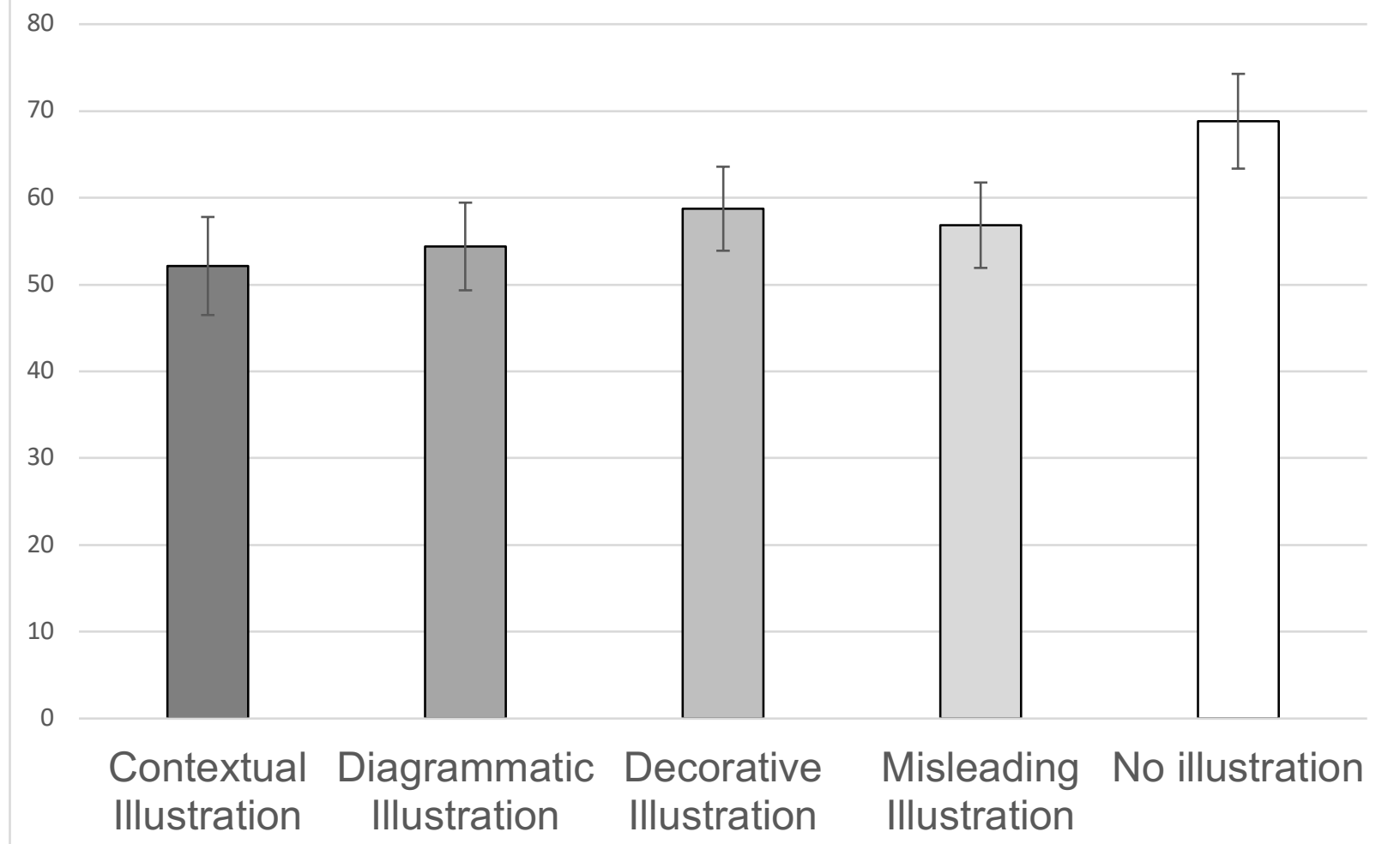

Figure 4. Average post-intervention quiz scores by condition (means and $+/-1$ standard error bars adjusted for the covariates of pretest and previous lesson performance) 
4.5

4

3.5

3

2.5

2.5

2

1.5

1
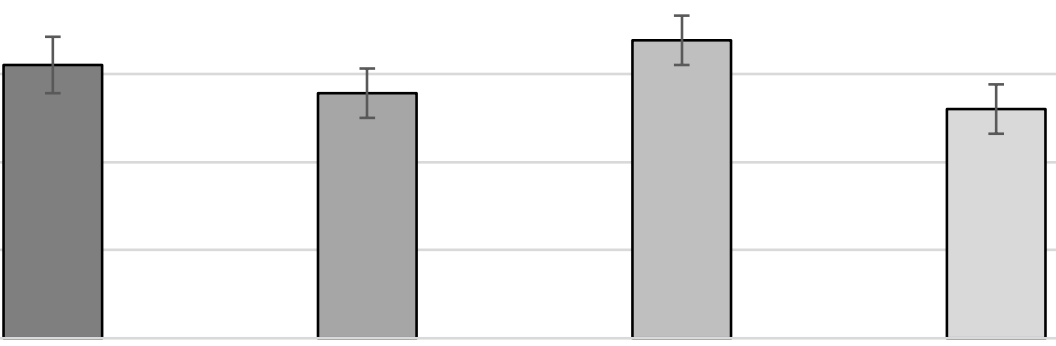

Contextual Diagrammatic Decorative Illustration Illustration Illustration

Misleading No illustration Illustration

Figure 5. Average lesson ratings by condition (means and $+/-1$ standard error bars adjusted for the covariates of previous lesson ratings) 
Q1 Let's use a table to investigate how the number of books I (used for shallow buy relates to the cost. I was at the bookstore the other personalization)

day. I bought 1 book, which cost 4 dollars. Then I decided that I wanted two copies of the book. How much will two books cost?

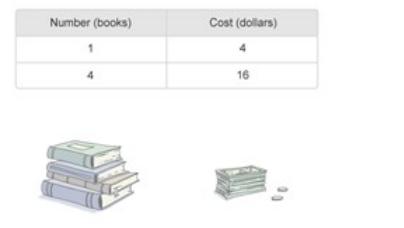

Q2

Kayla walks at a speed of 50 meters per minute. It takes Kayla

(used for deep personalization) 10 minutes to walk the distance of 500 meters to school. After school, it takes her 20 minutes to walk the distance of 1000 meters to the library. Her speed did not change. But the time increased. In fact, it increased by a factor of... what? After the library, Kayla walks to volleyball practice. The distance to volleyball practice is times the distance she walks to school. If Kayla's speed did not change, and the distance increased by a

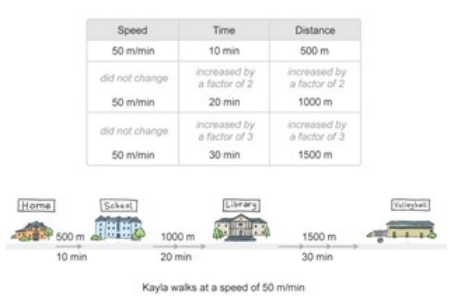
factor of 3, then what do you think happened to the time?

Figure 6. Control (non-personalized) problems in Experiment 2 


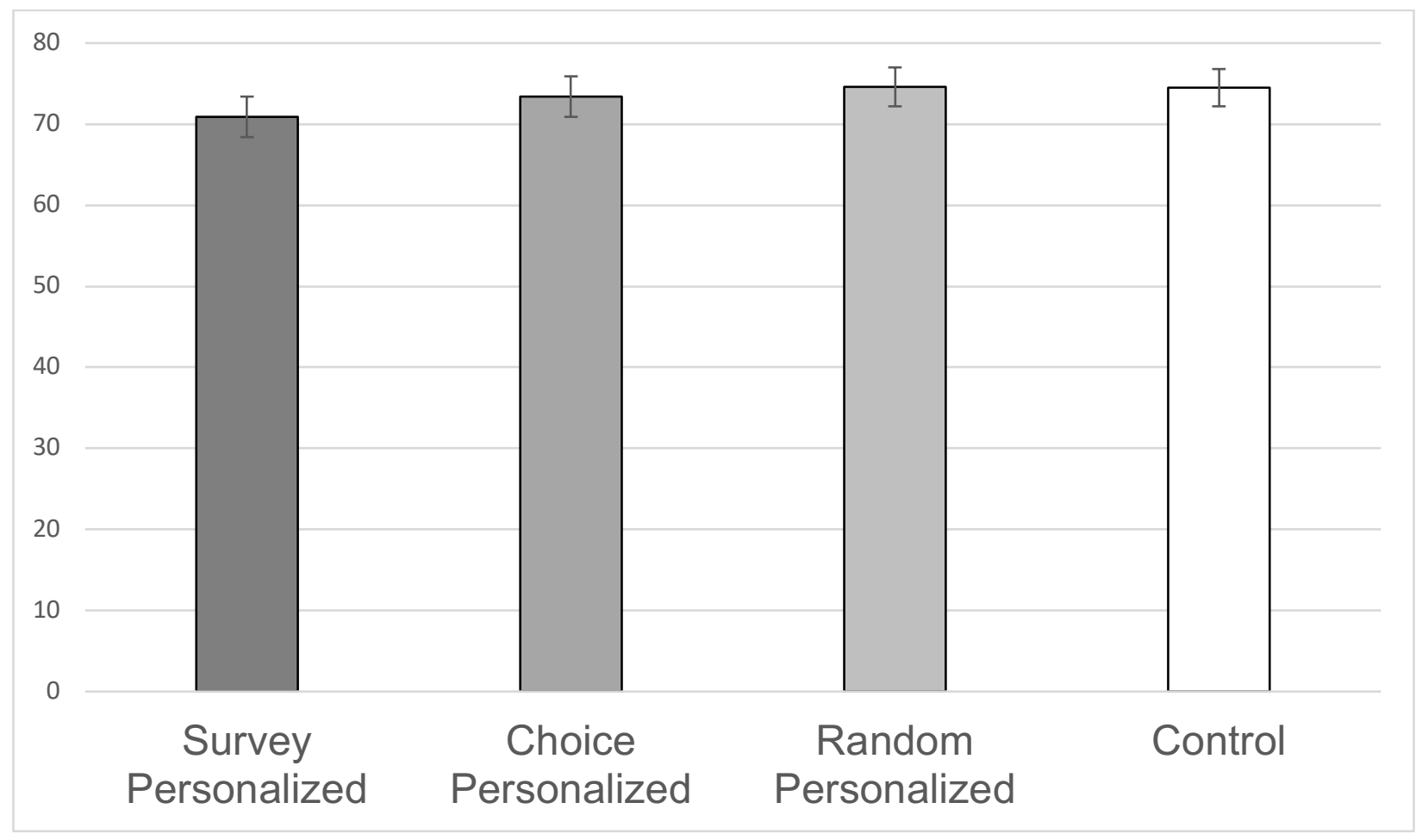

Figure 7. Average performance on the first problem (shallow personalization) by condition (means and $+/-1$ standard error bars adjusted for the covariates of mathematical knowledge) 


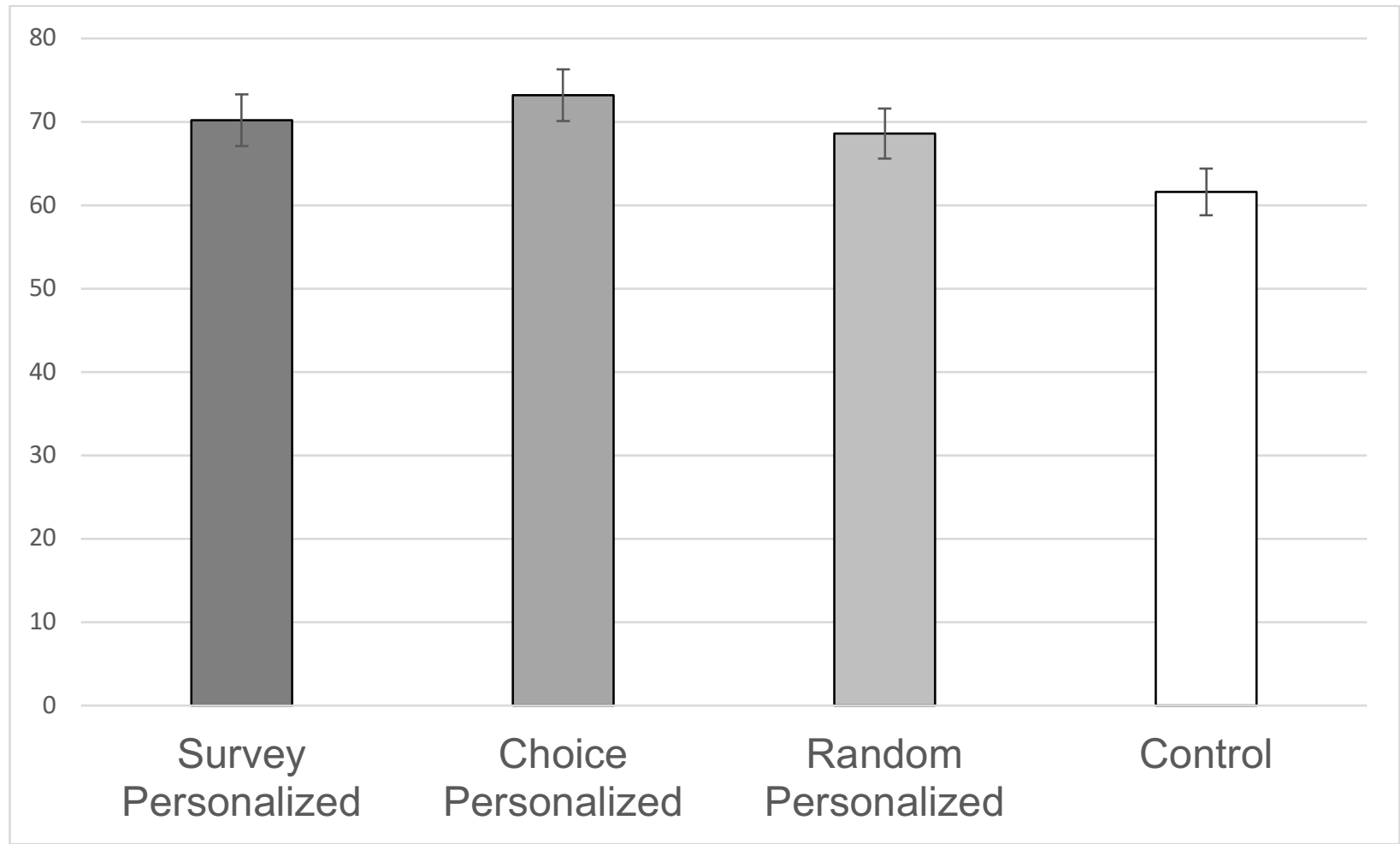

Figure 8. Average performance on the second problem (deep personalization) by condition (means and $+/-1$ standard error bars adjusted for the covariates of mathematical knowledge) 
Table 1

School Demographics and Performance

\begin{tabular}{lcc}
\hline Demographic Group & \% School A & \% School B \\
\hline Hispanic/Latino & 33.1 & 97.4 \\
Asian & 6.0 & 0 \\
Black or African American & 17.3 & 1.5 \\
Native Hawaiian or other Pacific Islander & 0.4 & 0 \\
White & 36.7 & 1.1 \\
Two or more races & 6.0 & 0 \\
Economically disadvantaged & 69.8 & 92.2 \\
LEP & 10.9 & 23.5 \\
Special Education & 4.8 & 6.7 \\
Gifted and Talented & 5.2 & 7.1 \\
2014 STAAR Mathematics Passing Rate & 30.2 & 24.3 \\
\hline
\end{tabular}

Note: LEP = Limited English Proficient, STAAR Mathematics is the mandatory standardized mathematics assessment students are required to take 
Table 2

Output for regression model of problem-solving accuracy for intervention problems (Experiment 1)

\begin{tabular}{|c|c|c|c|c|}
\hline Fixed effects & $B$ & $\mathrm{SE}(B)$ & $t$ value & $p$ value \\
\hline (Intercept) & 14.27 & 3.09 & 4.62 & $<.001$ \\
\hline Control & -3.41 & 3.44 & -.99 & .32 \\
\hline $\begin{array}{l}\text { Diagrammatic } \\
\text { illustration }\end{array}$ & (ref.) & & & \\
\hline $\begin{array}{l}\text { Contextual } \\
\text { illustration }\end{array}$ & -4.39 & 3.50 & -1.25 & .21 \\
\hline $\begin{array}{l}\text { Irrelevant } \\
\text { illustration }\end{array}$ & -4.53 & 3.22 & -1.41 & .16 \\
\hline $\begin{array}{l}\text { Misleading } \\
\text { illustration }\end{array}$ & -3.60 & 3.23 & -1.11 & .27 \\
\hline Previous unit test & .10 & .04 & 2.38 & .02 \\
\hline $\begin{array}{l}\text { Previous lesson } \\
\text { performance }\end{array}$ & .74 & .04 & 16.95 & $<.001$ \\
\hline
\end{tabular}


Table 3

Output for regression model of performance for post-intervention quiz (Experiment 1)

\begin{tabular}{lllll}
\hline Fixed effects & $B$ & $\mathrm{SE}(B)$ & $t$ value & $p$ value \\
\hline $\begin{array}{l}\text { (Intercept) } \\
\text { Control }\end{array}$ & $\begin{array}{l}38.40 \\
\text { (ref.) }\end{array}$ & 6.85 & 5.61 & $<.001$ \\
$\begin{array}{l}\text { Diagrammatic } \\
\text { illustration }\end{array}$ & -16.69 & 7.86 & -2.12 & .04 \\
$\begin{array}{l}\text { Contextual } \\
\text { illustration }\end{array}$ & -14.43 & 7.44 & -1.94 & .054 \\
$\begin{array}{l}\text { Irrelevant } \\
\text { illustration }\end{array}$ & -10.09 & 7.30 & -1.38 & .17 \\
$\begin{array}{l}\text { Misleading } \\
\text { illustration }\end{array}$ & -11.98 & 7.35 & -1.63 & .10 \\
$\begin{array}{l}\text { Previous unit } \\
\text { test }\end{array}$ & .46 & .09 & 5.092 & $<.001$ \\
$\begin{array}{l}\text { Previous lesson } \\
\text { performance }\end{array}$ & .20 & .09 & 2.12 & .04 \\
\hline
\end{tabular}


Table 4

Output for regression model of performance for the shallow personalization problem (Experiment 2)

\begin{tabular}{lllll}
\hline Fixed effects & $B$ & $\mathrm{SE}(B)$ & $t$ value & $p$ value \\
\hline $\begin{array}{l}\text { (Intercept) } \\
\text { Control }\end{array}$ & $\begin{array}{l}27.46 \\
\text { (ref.) }\end{array}$ & 6.01 & 4.57 & $<.001$ \\
$\begin{array}{l}\text { Survey } \\
\text { Personalized }\end{array}$ & -3.42 & 3.28 & -1.04 & .30 \\
$\begin{array}{l}\text { Choice } \\
\text { Personalized }\end{array}$ & -.71 & 3.31 & -.22 & .82 \\
$\begin{array}{l}\text { Random } \\
\text { Personalized }\end{array}$ & .12 & 3.22 & .04 & .97 \\
$\begin{array}{l}\text { Previous lesson } \\
\text { performance }\end{array}$ & 22.21 & 8.07 & 3.37 & $<.001$ \\
$\begin{array}{l}\text { Guided study } \\
\text { score }\end{array}$ & .40 & .12 & 3.41 & $<.001$ \\
\hline
\end{tabular}




\section{Table 5}

Output for regression model of performance for the deep personalization problem with the control as the reference (Experiment 2)

\begin{tabular}{lllll}
\hline Fixed effects & $B$ & $\mathrm{SE}(B)$ & $t$ value & $p$ value \\
\hline $\begin{array}{l}\text { (Intercept) } \\
\begin{array}{l}\text { Control } \\
\text { Survey }\end{array}\end{array}$ & $\begin{array}{l}-6.43 \\
\text { (ref.) }\end{array}$ & 7.53 & -.85 & .39 \\
$\begin{array}{l}\text { Personalized } \\
\text { Choice }\end{array}$ & 11.82 & 4.13 & 2.12 & .04 \\
$\begin{array}{l}\text { Personalized } \\
\text { Random }\end{array}$ & 7.05 & 4.15 & 2.85 & .005 \\
$\begin{array}{l}\text { Personalized } \\
\text { Previous lesson } \\
\text { performance }\end{array}$ & 42.01 & 4.04 & 1.75 & .08 \\
$\begin{array}{l}\text { Guided study } \\
\text { score }\end{array}$ & .55 & 10.13 & 4.15 & $<.001$ \\
\hline
\end{tabular}


Table 6

Output for regression model of performance for the deep personalization problem with the choice personalization as the reference condition (Experiment 2)

\begin{tabular}{lllll}
\hline Fixed effects & $B$ & $\mathrm{SE}(B)$ & $t$ value & $p$ value \\
\hline (Intercept) & 5.39 & 8.04 & .67 & .50 \\
$\begin{array}{l}\text { Control } \\
\text { Survey }\end{array}$ & -11.82 & 4.15 & -2.85 & .005 \\
$\begin{array}{l}\text { Personalized } \\
\text { Choice }\end{array}$ & -3.06 & 4.32 & -.71 & .48 \\
$\begin{array}{l}\text { Personalized } \\
\text { Random }\end{array}$ & (ref.) & & & \\
$\begin{array}{l}\text { Personalized } \\
\text { Previous lesson } \\
\text { performance }\end{array}$ & 42.01 & 4.20 & -1.13 & .26 \\
$\begin{array}{l}\text { Guided study } \\
\text { score }\end{array}$ & .55 & 10.13 & 4.15 & $<.001$ \\
\hline
\end{tabular}


Table 7

Output for regression model of performance for the posttest with the choice personalization condition as the reference (Experiment 2)

\begin{tabular}{lllll}
\hline Fixed effects & $B$ & $\mathrm{SE}(B)$ & $t$ value & $p$ value \\
\hline (Intercept) & 19.17 & 11.69 & 1.64 & .10 \\
$\begin{array}{l}\text { Control } \\
\text { Survey }\end{array}$ & -6.13 & 5.96 & -1.03 & .31 \\
$\begin{array}{l}\text { Personalized } \\
\begin{array}{l}\text { Choice } \\
\text { Personalized }\end{array}\end{array}$ & -9.07 & 6.17 & -1.47 & .14 \\
$\begin{array}{l}\text { Random } \\
\text { Personalized }\end{array}$ & -12.92 & 6.03 & & \\
$\begin{array}{l}\text { Previous lesson } \\
\text { performance }\end{array}$ & 19.09 & 14.59 & -2.14 & .03 \\
$\begin{array}{l}\text { Guided study } \\
\text { score }\end{array}$ & .38 & .22 & 1.31 & .19 \\
\hline
\end{tabular}


Table 8

Output for regression model of performance for the posttest with the control condition as the reference (Experiment 2)

\begin{tabular}{|c|c|c|c|c|}
\hline Fixed effects & $B$ & $\mathrm{SE}(B)$ & $t$ value & $p$ value \\
\hline (Intercept) & 13.05 & 11.05 & 1.18 & .24 \\
\hline Control & (ref.) & & & \\
\hline Survey & -2.95 & 5.91 & -.50 & .62 \\
\hline Personalized & & & & \\
\hline $\begin{array}{l}\text { Choice } \\
\text { Personalized }\end{array}$ & 6.13 & 5.96 & 1.03 & .31 \\
\hline $\begin{array}{l}\text { Random } \\
\text { Personalized }\end{array}$ & -6.79 & 5.81 & -1.17 & .24 \\
\hline $\begin{array}{l}\text { Previous lesson } \\
\text { performance }\end{array}$ & 19.10 & 14.59 & 1.31 & .19 \\
\hline $\begin{array}{l}\text { Guided study } \\
\text { score }\end{array}$ & .38 & .21 & 1.74 & .08 \\
\hline
\end{tabular}

